\title{
Revisiting the Crystal Structure of BaCe0.4Zr0.4Y0.2O3- Proton Conducting Perovskite and its Correlation with Transport Properties
}

Basbus, Juan F.; Arce, Mauricio D.; Napolitano, Federico R.; Troiani, Horacio E.; Alonso, José Antonio; Saleta, Martin E.; Gonzalez, Miguel Angel; Cuello, Gabriel J.; Fernández-Diaz, Maria Teresa; Pardo Sainz, Miguel

Total number of authors:

17

Published in:

Applied Energy Materials

Link to article, DOI:

10.1021/acsaem.9b02498

Publication date:

2020

Document Version

Publisher's PDF, also known as Version of record

Link back to DTU Orbit

Citation (APA):

Basbus, J. F., Arce, M. D., Napolitano, F. R., Troiani, H. E., Alonso, J. A., Saleta, M. E., Gonzalez, M. A., Cuello, G. J., Fernández-Diaz, M. T., Pardo Sainz, M., Bonanos, N., Jimenez, C., Giebeler, L., Figueroa, S. J. A., Caneiro, A., Serquis, A. C., \& Mogni, L. V. (2020). Revisiting the Crystal Structure of BaCe $\mathrm{Zr}$ Y0.2O Proton Conducting Perovskite and its Correlation with Transport Properties. Applied Energy AMatertals, 3(3); 2881-2892. https://doi.org/10.1021/acsaem.9b02498

\section{General rights}

Copyright and moral rights for the publications made accessible in the public portal are retained by the authors and/or other copyright owners and it is a condition of accessing publications that users recognise and abide by the legal requirements associated with these rights.

- Users may download and print one copy of any publication from the public portal for the purpose of private study or research.

- You may not further distribute the material or use it for any profit-making activity or commercial gain

- You may freely distribute the URL identifying the publication in the public portal 


\title{
Revisiting the Crystal Structure of $\mathrm{BaCe}_{0.4} \mathrm{Zr}_{0.4} \mathrm{Y}_{0.2} \mathrm{O}_{3-\delta}$ Proton Conducting Perovskite and Its Correlation with Transport Properties
}

\author{
Juan F. Basbus,* Mauricio D. Arce, Federico R. Napolitano, Horacio E. Troiani, José A. Alonso, \\ Martín E. Saleta, Miguel A. González, Gabriel J. Cuello, María T. Fernández-Díaz, Miguel Pardo Sainz, \\ Nikolaos Bonanos, Catalina E. Jimenez, Lars Giebeler, Santiago J. A. Figueroa, Alberto Caneiro, \\ Adriana C. Serquis, and Liliana V. Mogni
}

Cite This: ACS Appl. Energy Mater. 2020, 3, 2881-2892

Read Online

ACCESS | Lلll Metrics \& More | 国 Article Recommendations | sl Supporting Information

ABSTRACT: Oxides with proton conductivity have a great potential for applications in environmental energy technology. Despite the $\mathrm{Ba}$ $\mathrm{Ce}_{0.4} \mathrm{Zr}_{0.4} \mathrm{Y}_{0.2} \mathrm{O}_{3-\delta}(\mathrm{BCZY})$ perovskites being well-known proton conductors, it is a challenge to determine the optimal operating temperature range where the energy applications benefit most from this unique property. The protonic transport properties strongly depend on crystal structure and local distortions in the participating cation coordination sphere, according to related temperatures and gas feed. The transport and crystallographic properties of BCZY were simultaneously studied by impedance spectroscopy (IS) and synchrotron X-ray diffraction (S-XRD). A strong correlation between conductivity and the lattice parameter, corresponding in principle to a cubic symmetry, was observed, mainly between 400 and $700{ }^{\circ} \mathrm{C}$. The protonic

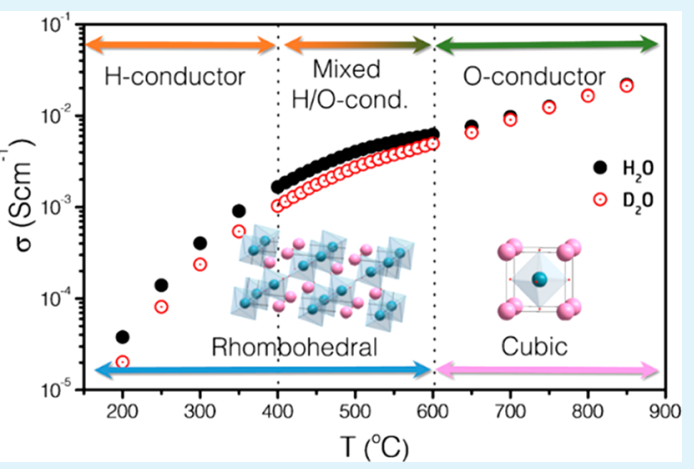
conductivity range was analyzed by the $\mathrm{H} / \mathrm{D}$ isotopic effect on the impedance spectra, which helped to identify protonic conduction as the governing transport mechanism below $600{ }^{\circ} \mathrm{C}$, while the transport via oxygen vacancies dominates above this temperature. In order to assess the real crystallographic structure, the simultaneous refinement of laboratory $\mathrm{XRD}$ and neutron diffraction (ND) patterns was performed. According to this, BCZY changes from rhombohedral symmetry below $400{ }^{\circ} \mathrm{C}$ to cubic at $600{ }^{\circ} \mathrm{C}$ in a second-order phase transition. Complementary quasielastic neutron scattering (QENS) enables us to determine a protonic jump length of $3.1 \AA$, which matches the O-O distances in the octahedral oxygen coordination sphere around the cations. These results support the protonic self-diffusion through proton hopping between intraoctahedral $\mathrm{O}$ sites as the main transport mechanism up to $600{ }^{\circ} \mathrm{C}$.

KEYWORDS: $\mathrm{BaCe}_{0.4} \mathrm{Zr}_{0.4} Y_{0.2} \mathrm{O}_{3-\delta}$ (BCZY) protonic conductor, transport nature mechanism, isotopic effect, neutron techniques, protonic self-diffusion, crystallographic properties

\section{INTRODUCTION}

Barium cerates and zirconates are oxides able to transport protons through their crystal structure, by proton hopping between perovskite O-sites. ${ }^{1,2}$ This feature makes them potential candidates as hydrogen sensors, ${ }^{3}$ as membranes for hydrogen purification ${ }^{4}$ and isotopic exchange of $\mathrm{H} / \mathrm{D} / \mathrm{T},{ }^{5}$ and as electrolytes for proton conducting solid oxide fuel cells (PCSOFC) and solid oxide electrolyzer cells (PC-SOEC). ${ }^{6}$ Recently, $\mathrm{BaCe}_{0.4} \mathrm{Zr}_{0.4} \mathrm{Y}_{0.2} \mathrm{O}_{3-\delta}(\mathrm{BCZY})$ perovskites were proposed as a potential PC-SOFC electrolyte due to its high bulk protonic conductivity and good $\mathrm{CO}_{2}$ tolerance. ${ }^{7-15}$ However, our previous work suggests that $\mathrm{BCZY}$ is a protonic conductor only below $600{ }^{\circ} \mathrm{C}$. ${ }^{13}$ In all of the above listed applications, BCZY is exposed to extreme operational conditions (high electrical current, temperature, pressure, oxidizing/reducing atmospheres, etc.) leaving the doubt if the transport properties would be affected by external factors such as changes in the chemical potential, electric fields, etc. The simultaneous characterization of crystallographic, electrochemical, and thermodynamic properties allows us to understand and predict the behavior of the material under realistic operating conditions. In this sense, in situ/in operando characterization techniques cover a major field of capabilities under development at worldwide large facilities ${ }^{16-18}$ and, to an extensive scale, on laboratory level. ${ }^{19}$ Many examples of these techniques were applied to the study of materials related to batteries, ${ }^{20-32}$ SOFCs, ${ }^{33-39}$ and catalysis. ${ }^{40-42}$ However, the

Received: December 23, 2019

Accepted: February 17, 2020

Published: February 17, 2020 
kind of simultaneous measurements conducted in this work has not yet been reported for protonic conductor materials, despite the fact that the simultaneous characterization of crystallographic and electrochemical properties is fundamental for understanding $\mathrm{H}$-transport processes as well as PC-SOFC limitations and advantages.

In addition, neutron-based techniques can provide some powerful tools for the characterization of protonic conductor materials. ${ }^{43}$ Quasielastic neutron scattering (QENS) ${ }^{44-49}$ and neutron diffraction (ND) $)^{50-53}$ are complementary techniques that allow evaluating transport and crystallographic properties, respectively. QENS is a technique that allows determining $\mathrm{H}$ diffusive dynamics and diffusion coefficients by profiting from the large incoherent neutron scattering cross section of hydrogen. Neutron diffraction is highly suitable for the determination of O-related crystallographic parameters due to the better contrast between elastic scattering cross sections compared to powder XRD and may help to determine crystal symmetry, space groups, oxygen content and positions, octahedral tilting, etc. This technique is also useful to determine the crystallographic position of hydrogen in the perovskite structure; they can be identified by comparing dry and deuterated samples (i.e., deuterium has a positive elastic scattering cross section while hydrogen shows a negative one). These techniques have been used in the past to study proton conductors. For example, Malavasi et al. studied $\mathrm{Ba}(\mathrm{Ce}, \mathrm{Zr}, \mathrm{Y})$ $\mathrm{O}_{3-\delta}$ perovskites by combination of ND and synchrotron X-ray diffraction $(\mathrm{S}-\mathrm{XRD})^{54}$ and reported several phase transitions (monoclinic, orthorhombic, rhombohedral, and cubic symmetries). Noferini et al. used QENS to determine hydrogen diffusion constants, jump lengths, and activation energies for $\mathrm{Ba}(\mathrm{Zr}, \mathrm{Sc}, \mathrm{In}, \mathrm{Y}) \mathrm{O}_{3-\delta}$ compounds and proved the feasibility of this technique to study hydrogen transport phenomena in perovskites. $^{55}$

In this work, we present an in situ study on crystallography and conductivity of a BCZY ionic conductor by means of S$\mathrm{XRD}$ and impedance spectroscopy (IS), respectively. The protonic conductivity was evaluated by experiments on the isotopic effect via IS with the aim to prove the temperature range of this unique property and the operating conditions for the energy applications. Proton transport parameters such as diffusion coefficient and jump lengths were also calculated from QENS data of hydrated samples until $600{ }^{\circ} \mathrm{C}$. Crystallographic information was obtained by combining laboratory $\mathrm{XRD}$ and $\mathrm{ND}$, in order to reveal the structure of BCZY until $600{ }^{\circ} \mathrm{C}$. Results from complementary techniques at room temperature such as transmission electron microscopy (TEM) and X-ray absorption spectroscopy (XAS) were discussed with the aim to point out how, sometimes, these techniques are inadequate to reveal the crystal structure of oxides. This work also emphasizes the need to perform in situ experiments and to test proton conductivity in $\mathrm{H}_{2} \mathrm{O} / \mathrm{D}_{2} \mathrm{O}$ containing atmospheres to prove the protonic nature of conductivity. In addition, the combination of X-ray with neutron techniques is essential for a complete understanding of the $\mathrm{H}$-transport mechanism and the influence of the crystal structure, which makes the exact characterization of the BCZY crystal structure necessary to enable a realistic correlation with the observed hydrogen transport properties.

\section{EXPERIMENTAL SECTION}

Sample Preparation and Preliminary Structural Characterization. The BCZY perovskite was synthesized by a solid state reaction and sintered at $1600{ }^{\circ} \mathrm{C}$ for $12 \mathrm{~h} .{ }^{13}$ Sintered pellets were ground in an agate mortar when powders were required. Phase purity was checked by laboratory XRD using a PANalytical Empyrean diffractometer with $\mathrm{Cu} \mathrm{K} \alpha$ radiation, graphite monochromator, and PIXcel $^{3 \mathrm{D}}$ detector in Bragg-Brentano geometry in the range $10-120^{\circ}$ 20. X-ray pattern analysis was performed by applying the Rietveld method with Fullprof and a BCZY structure model with the space group $P m \overline{3} m$. $^{13}$

Particle and crystalline shapes of the BCZY powder were studied by TEM by using a Philips CM 200UT microscope at an acceleration voltage of $200 \mathrm{kV}$, where overview and high resolution bright field images were obtained. SAED patterns were collected and indexed with the same structural model used for XRD to check crystallographic parameters. Elementary analysis was performed by energy dispersive spectroscopy (EDS).

XAS measurements were collected at the LNLS XAFS1 DB04 beamline at $\mathrm{Zr}$ K-edge between 17.8 and $19.0 \mathrm{keV}$ in transmission geometry ${ }^{56}$ at room temperature. Energy calibration was performed by placing a $\mathrm{Zr}$ metal foil standard between the second and third ionization chamber. Previous to these measurements, BCZY powders were dried at $800{ }^{\circ} \mathrm{C}$ under synthetic air to simplify data analysis. In addition, $\mathrm{BCZY}$ powders were diluted with $\mathrm{BN}$ to reduce radiation absorption and were pressed to pellets. Data were analyzed using the Demeter package. ${ }^{57} \mathrm{X}$-ray absorption near edge spectroscopy (XANES) data were compared with $\mathrm{BaZrO}_{3}$ spectra collected in the same conditions. Theoretical backscattering paths were calculated with the FEFF6 code $^{58}$ using the structure model obtained from the Rietveld analysis of the diffraction patterns acquired from the same samples. Both cubic and rhombohedral structures were also accounted for in the modeling of the extended X-ray absorption fine structure (EXAFS) data range. These calculations were performed using $\mathrm{BaZrO}_{3}$ as a structural model. The cluster size was delimited within a 12 A radius sphere. EXAFS signal were Fourier transformed in the range of photoelectron wavenumber $k=2.709-13$ $\AA^{-1}$ by applying a Kaiser-Bessel window $\left(\mathrm{d} k=1 \AA^{-1}\right)$. The first coordination sphere was fitted in the real space $R$ in the range $R=$ 1.25-1.93 $\AA$ using $k$-weights of 1,2 , and 3 simultaneously, and without constraints in the geometrical parameters (only coordination number $N$ was maintained fixed at 6), obtaining an $R$-factor of 0.018 .

Simultaneous Characterization: In Situ Crystallographic and Conductivity Study. S-XRD patterns and IS spectra were simultaneously collected between room temperature and $800{ }^{\circ} \mathrm{C}$ in a gas feed of wet $\left(\sim 2 \% \mathrm{H}_{2} \mathrm{O}\right)$ synthetic air $\left(20 \% \mathrm{O}_{2} / \mathrm{N}_{2}\right)$ with $100 \mathrm{~mL} /$ min. A homemade sample holder and furnace ${ }^{59}$ were used to study the electrical and structural properties simultaneously under in situ conditions (see the Supporting Information). A dense square BCZY bar $(\sim 0.5 \times 0.5 \times 0.1 \mathrm{~cm})$ was used for a better determination of high temperature bulk conductivity and optimal irradiated surface.

Diffraction patterns as a function of temperature were collected at the LNLS XPD-D10B beamline ${ }^{60}$ in the high intensity mode by a Dectris Mythen $1 \mathrm{~K}$ linear position sensitive detector for $2 \theta$ between 20 and $100^{\circ}$. The wavelength was calibrated to 1.5488 (1) $\AA$ by using

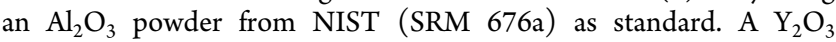
standard was used to determine the instrumental resolution function and an ionization chamber was used as monitor to normalize the photon flux. The crystal structures were obtained by the refinement of the structure models with the S-XRD data by the Rietveld method using sequential mode of the FullProf Suite software ${ }^{61}$ based on the cubic $P m \overline{3} m$ space group reported at room temperature. ${ }^{7,8,12}$ A Thompson-Cox-Hastings pseudo-Voigt convoluted with axial divergence asymmetry function was used to fit the peak shape. ${ }^{62}$ The microstructural parameters, such as those related to crystallite size and microstrain effects, were calculated by using an isotropic model.

Electrical conductivity of the BCZY sintered bar was studied by IS. Silver ink was used to prepare a current collector on parallel opposing sides of the BCYZ bar. Measurements were performed by using a BioLogic SP-300 potentiostat/galvanostat, from $7 \mathrm{MHz}$ to $0.1 \mathrm{~Hz}$ at a $50 \mathrm{mV}$ amplitude. IS spectra were fitted with the electrochemical equivalent circuit (EEC), by using Zview2 software according to 
previous results. ${ }^{13}$ Before simultaneous S-XRD and IS measurements were performed, the sample was annealed at $800{ }^{\circ} \mathrm{C}$ for $2 \mathrm{~h}$ and then at $400{ }^{\circ} \mathrm{C}$ for $4 \mathrm{~h}$ under wet synthetic air, to ensure full hydration of the BCZY dense sample.

Proton Conductivity Verification. The isotopic effect on BCZY conductivity was studied by IS to check the temperature range of protonic conductivity, collecting data between 200 and $900{ }^{\circ} \mathrm{C}$, under synthetic air $\left(20 \% \mathrm{O}_{2} / \mathrm{N}_{2}\right)$ humidified with regular or heavy water vapor $\left(\sim 2 \% \mathrm{H}_{2} \mathrm{O}\right.$ or $\sim 2 \% \mathrm{D}_{2} \mathrm{O}$, respectively). Measurements were performed using an Autolab PGSTAT30 potentiostat/galvanostat, from $1 \mathrm{MHz}$ to $0.1 \mathrm{~Hz}$ with a $50 \mathrm{mV}$ amplitude. Impedance spectra were similarly fitted to those collected for in situ tests. The electrical transport analysis was complemented with room temperature permittivity measurements of BCZY under atmospheric air. These measurements were performed between $300 \mathrm{kHz}$ and $20 \mathrm{~Hz}$ with a Wayne-Kerr 6425 precision component analyzer, a metal box rig, and silver ink as collector. The permittivities of BCZY sintered bars were measured horizontally $(\sim 0.5 \mathrm{~cm}$ distance) and vertically $(\sim 0.1 \mathrm{~cm})$ by applying 1000 and $200 \mathrm{mV}$ amplitudes, respectively. Previously, the sample was annealed (i) at $800{ }^{\circ} \mathrm{C}$ during $2 \mathrm{~h}$ and then at $400{ }^{\circ} \mathrm{C}$ for $4 \mathrm{~h}$ both under distilled water vapor and (ii) with the same conditions as for (i) but under heavy water vapor both corresponding to oxidizing atmospheres. These annealings allow us to saturate the oxygen vacancies with $\mathrm{H}_{2} \mathrm{O}$ or $\mathrm{D}_{2} \mathrm{O}$.

Additionally, the hydrogen diffusion coefficient was determined by QENS. The spectra of BCZY were collected at several temperatures while heating between room temperature and $800{ }^{\circ} \mathrm{C}$ under an atmospheric air flow of $100 \mathrm{~mL} / \mathrm{min}$. Spectra were collected at the backscattering spectrometer IN16B, at the ILL, using an incident wavelength of $6.271 \AA$ and $\mathrm{Si}$ (111) unpolished analyzers. ${ }^{63}$ IN16B has an energy resolution of $\sim 0.75 \mu \mathrm{eV}$ and minimum and maximum momentum transfers $\left(Q=\frac{4 \pi}{\lambda} \sin \theta\right)$ of 0.2 and $1.9 \AA^{-1}$, respectively. Spectra were collected using the high flux (HF) standard position. Initially, the BCZY powder was annealed in a quartz tube at $400{ }^{\circ} \mathrm{C}$ for $2 \mathrm{~h}$ in wet air, in order to ensure that it was completely hydrated. Then the quartz tube was mounted in a furnace and a heating run between room temperature and $800{ }^{\circ} \mathrm{C}$ was performed. QENS spectra were taken at several temperatures, and additionally the intensity in the elastic channel at $\hbar \omega=0$ (elastic fixed window scan EFWS) and inelastic channel $\hbar \omega=2 \mu \mathrm{eV}$ (inelastic fixed window scan IFWS) were collected during the heating steps. QENS spectra were corrected (background subtraction, normalization by vanadium, and conversion to $Q$ and energy transfer) using Lamp. ${ }^{64}$ Detectors where the signal was strongly contaminated by coherent scattering corresponding to Bragg reflections were then discarded. Due to the large incoherent cross section of hydrogen, QENS is particularly sensible to proton motion. Thus, in our sample, almost half of the neutron scattering signal comes from absorbed water molecules, in spite of their small concentration. Furthermore, the remaining signal is fundamentally coherent and is concentrated on the Bragg peaks, so once they are removed, the remaining signal represents, to a very good approximation, the incoherent QENS of protons in the BCZY powder. Therefore, the corrected dynamic structure factors $S(Q \hbar \omega)$ obtained within the dynamic range of $30 \mu \mathrm{eV}$ were fitted to a model for incoherent QENS consisting of a sum of a delta function and a Lorentzian whose width is given by the Chudley-Elliot Model (CEM). ${ }^{65}$ This model is then convoluted with the instrument resolution (obtained from the measurement of a vanadium standard) and a flat background is added. Such a model has already been used by Noferini et al. to analyze the QENS dynamics in another series of proton conducting perovskites. ${ }^{55}$

At each temperature, 12 spectra were obtained and fitted using 3 main $Q$-independent parameters $\left(f_{0}, l\right.$, and $\tau$; see below) plus a set of auxiliary $Q$-dependent parameters to account for the arbitrary intensity scale and a flat background (see eq 3 ). As there is a strong correlation between $f_{0}$ and $\tau$, on a second step the value of $f_{0}$ was fixed, $l$ was also fixed to the average jump length obtained from the first set of fits at all temperatures considered 3.4(1) $\AA$, and only the mean residence time was refined.
Detailed Structural Characterization. ND patterns of prehydrated BCZY powder were collected at room temperature, 200, 400, and $600{ }^{\circ} \mathrm{C}$ under atmospheric air. ND patterns were acquired at the ILL D2B instrument using a wavelength of $1.594 \AA$ and the high flux mode. The BCZY powder was mounted in a vanadium can for room temperature measurement and in a quartz sample holder inside an induction furnace with a thin vanadium foil heater for high temperature measurement in atmospheric air. Additionally, laboratory XRD patterns of the same samples were collected using an Anton Paar HTK1200 high temperature chamber coupled to the above-described PANalytical Empyrean diffractometer. The instrumental profiles were obtained from diffraction standards. XRD and ND patterns were simultaneously fitted by the Rietveld method using the multipattern fit mode of the Fullprof Suite with a common structural model according to reference. ${ }^{54}$ Thompson-Cox-Hastings pseudo-Voigt convoluted with axial divergence asymmetry function was considered for peak profiles. The oxygen occupancy, atom positions and isotropic atomic displacement parameters were refined and related to the structural distortion. The ND background was refined with a linear interpolation of $\mathrm{N}$ selected points, while the XRD background was modeled with a Chebyshev polynomial. Crystallite size and isotropic microstrain were also evaluated. In a previous work, the water content on prehydrated powder was analyzed by thermogravimetry (TG) under a dry oxidizing atmosphere. ${ }^{13}$ Nuclear and electron density distributions were analyzed by a combination of the maximum entropy method (MEM) with Rietveld analysis using the Dysnomia software. ${ }^{66}$ The MEM applied to XRD and ND patterns allows us to reconstruct the electronic and nuclear density maps, respectively. ${ }^{67,68}$ For example, for polycrystalline XRD data, the well-known phase problem prevents us from determining the charge density by an inverse Fourier transform applied to the observed crystal structure factors. However, MEM can infer the unobserved crystal structure factors from the observed ones and maximizes the entropic information. ${ }^{69,70}$ Also, MEM provides the experimental evidence of a bonding state, atomic disorder, and ion conduction into crystal structures. Many examples of MEM applied to material science can be found in the references. ${ }^{71-74}$ The resulting electronic and nuclear density distribution maps were visualized with the VESTA software. ${ }^{75}$

\section{RESULTS AND DISCUSSION}

Preliminary Structural Characterization. The XRD pattern of BCZY powder acquired in the laboratory at room temperature is indexed according to the cubic $P m \overline{3} m$ space group. ${ }^{7,8,12,13}$ Additionally, the interplanar $d$-spacing $\left(d_{h k l}\right)$ values as estimated from Selected Area Electron Diffraction (SAED) patterns indicate a good match with those calculated from XRD.

XAS allows us to determine oxidation states and location of dopants in some zirconium and cerium perovskites. ${ }^{76-80}$ From BCZY spectral analysis, $\mathrm{Zr}^{4+}$ is 6-fold coordinated to oxygen atoms in an octahedral cluster of the cubic structure. However, it is not possible to resolve small distortions in the first coordination spheres between rhombohedral and cubic symmetries. This preliminary characterization suggests that BCZY presents a cubic symmetry at room temperature. For more experimental details and a broad discussion, see the Supporting Information.

Simultaneous Characterization: In Situ Crystallographic and Conductivity Study. It is expected that protonic conductivity of BCZY dominates the transport mechanism in nonenvironmental operating conditions. However, under these conditions, the crystalline structure may be subjected to changes, affecting the ionic transport. That is why it is interesting to perform a simultaneous characterization of ionic conductivity and crystal structure to understand and predict the behavior of the material under realistic operating 
conditions. The Nyquist plot and S-XRD pattern of BCZY simultaneously obtained at $400{ }^{\circ} \mathrm{C}$ in wet synthetic air are displayed in Figure 1a,b, respectively. For the Rietveld analyses the same cubic crystallographic model as for the laboratory XRD data was applied. At $400{ }^{\circ} \mathrm{C}$, the calculated lattice parameter is 4.318(1) $\AA$, which is consistent with our previous results from laboratory high-temperature XRD experiments $(4.324(1) \AA) .{ }^{13}$ The Nyquist plot presents two arcs that were fitted by using an EEC composed of two electrical circuits in series, each one composed by a resistance $R$ in parallel with a constant phase element CPE. The high-frequency arc corresponds to the total BCZY impedance due to the overlap between bulk and grain boundary conductivity contributions. ${ }^{13}$ The conductivity $\sigma$ was obtained from the real axis interception of the high frequency arc (see $\sigma^{-1}$ in Figure 1a), normalized by geometry and then corrected for the sample porosity ( $22 \%$ ) according to our previous work. ${ }^{13}$ So, for instance, at $400{ }^{\circ} \mathrm{C}$ in wet synthetic air, BCZY displayed a high frequency arc with $\sigma \approx 0.002 \mathrm{~S} \mathrm{~cm}^{-1}$, a relaxation frequency $f_{\max }=100 \mathrm{kHz}$, and capacitance $C=8 \mathrm{nFcm}^{-1}$. The corresponding activation energy $E_{\mathrm{a}}$ is $0.45 \mathrm{eV}$. It was proposed that the bulk transport mechanism of electrical charges in $\mathrm{Ba}(\mathrm{Ce}, \mathrm{Zr}, \mathrm{Y}) \mathrm{O}_{3-\delta}$ protonic conductors involves (i) hydroxide $\mathrm{OH}_{\mathrm{O}}^{\bullet}$ formation by water vapor incorporation into oxygen vacancies $\mathrm{V}_{\mathrm{O}}^{\bullet \bullet}$ and (ii) interstitial proton hopping through oxygen sites $\mathrm{O}_{\mathrm{O}}^{x}$ into the structure. ${ }^{12}$ The first step corresponds to the hydration reaction $\mathrm{V}_{\mathrm{O}}^{\bullet \bullet}+\mathrm{H}_{2} \mathrm{O}+\mathrm{O}_{\mathrm{O}}^{x} \leftrightarrows 2 \mathrm{OH}_{\mathrm{O}}^{\bullet}$ and the second one to the hydrogen jump by an $\mathrm{O}_{\mathrm{O}}-\mathrm{H}^{\bullet} \cdots \mathrm{O}_{\mathrm{O}}^{x}$ exchange, following a random migration path. A bulk protonic conduction mechanism is characterized by a low activation energy $(0.2-0.6 \mathrm{eV})^{81}$ and high proton solubility up to 600 ${ }^{\circ} \mathrm{C}$. ${ }^{6,82}$ The obtained $E_{\mathrm{a}}=0.45 \mathrm{eV}$ suggests that the major influence on the total conductivity is a bulk contribution. ${ }^{13}$ The low $E_{\mathrm{a}}$ value is in agreement with that of other cubic $\mathrm{BaZr}_{0.9} \mathrm{Y}_{0.1} \mathrm{O}_{3-\delta}$ perovskites, which show a decrease on $E_{\mathrm{a}}$ with the increase of the lattice parameter. ${ }^{83,84}$ However, note that this capacitance value is larger than those related to typical bulk conductivities, which are around $\sim 0.001 \mathrm{nF} \mathrm{cm}^{-1}$, leading to the question of whether a geometrical factor may be affecting the capacitance values during the IS experiments. In order to check for a possible geometrical influence, relative permittivity $(\varepsilon)$ measurements as a function of frequency were performed on BCZY dense samples at room temperature under air atmosphere. The obtained $\varepsilon$ values were compared at two different length/area $(l / A)$ ratios: alongside the bar $(\sim 0.5$ $\mathrm{cm}$ distance and $\left.l / A \sim 10 \mathrm{~cm}^{-1}\right)$ and between faces $(\sim 0.1 \mathrm{~cm}$ and $\left.l / A \sim 0.4 \mathrm{~cm}^{-1}\right)$. Remarkably, both measurements show the same trend with $\varepsilon$ values of 122 and 15 at $20 \mathrm{~Hz}$ and 300 $\mathrm{kHz}$, respectively. An explanation of this effect is that for large $l / A$ factors, a stray capacitance can swamp the bulk capacitance. $^{85}$ This kind of effect was already reported by other authors but for thin-films of doped barium zirconates. For example, capacitance valuesaround $100 \mathrm{nF} \mathrm{cm}^{-1}$ were already reported for $1 \mu \mathrm{m}$ thick $\mathrm{BaZr}_{0.8} \mathrm{Y}_{0.2} \mathrm{O}_{3-\delta}$ epitaxial films grown on $\mathrm{MgO}$ and $\mathrm{Al}_{2} \mathrm{O}_{3} .{ }^{86}$ Also, bulk conductivity, relaxation frequency and capacitance of $\sim 0.02 \mathrm{~S} \mathrm{~cm}^{-1}, 20$ $\mathrm{kHz}$, and $170 \mathrm{nF} \mathrm{cm}^{-1}$, respectively, were reported for $\mathrm{BaZr}_{0.8} \mathrm{Y}_{0.2} \mathrm{O}_{3-\delta}$ films measured at $400{ }^{\circ} \mathrm{C}$ under wet diluted hydrogen. ${ }^{86}$

Figure 1c shows the simultaneous evolution of conductivity $\sigma$ and lattice parameter $a$ as a function of temperature $T$ under a wet synthetic air feed. Conductivity and lattice parameter increase linearly between 200 and $480{ }^{\circ} \mathrm{C}$ and above $540{ }^{\circ} \mathrm{C}$.
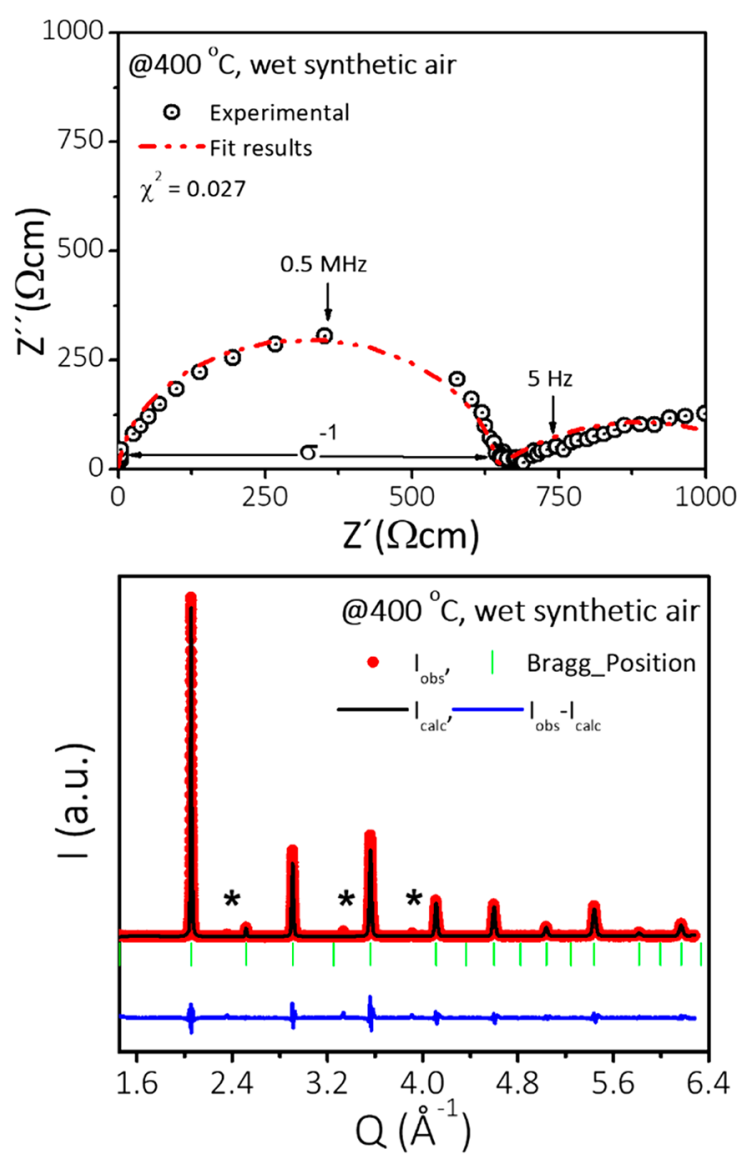

in-situ measurements, wet synthetic air

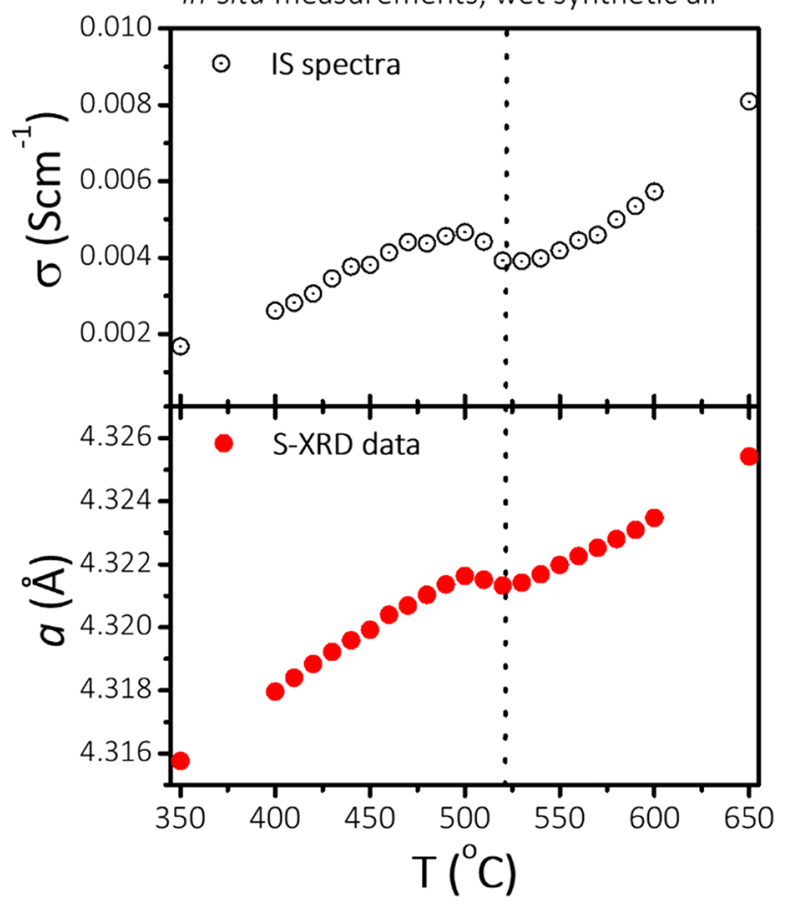

Figure 1. Simultaneous data acquisition of BCZY bar. (a) IS spectrum and (b) S-XRD data collected at $400{ }^{\circ} \mathrm{C}$ in wet synthetic air. The peaks indicated as "*” on the diffraction pattern correspond to traces of $\mathrm{Ag}$ ink and $\mathrm{Al}_{2} \mathrm{O}_{3}$. (c) Conductivity and lattice parameter obtained from IS and S-XRD simultaneous measurements as a function of temperature.

On the contrary, there is a conductivity reduction and lattice compression between 490 and $530{ }^{\circ} \mathrm{C}$. The correlation 
between conductivity and structure changes observed here is in agreement with those proposed by Malavasi et al. for the parent $\mathrm{BaCe}_{0.8} \mathrm{Y}_{0.2} \mathrm{O}_{2.9}$ protonic conductor perovskite, which presents several phase transitions (monoclinic, orthorhombic, rhombohedral, and cubic) between room temperature and 800 ${ }^{\circ} \mathrm{C} .{ }^{53}$ These authors suggest that the slope change observed in the electrical conductivity up to $500{ }^{\circ} \mathrm{C}$ would be associated with phase transitions from orthorhombic to rhombohedral symmetry. Moreover, they did not exclude that the slope change could also be associated with a transport mechanism change. However, our HT-XRD pattern data are indexed with the above-mentioned cubic symmetry in the whole temperature range according to bibliography. ${ }^{7-14}$ We have strong hints to propose that the same trend observed for conductivity and lattice parameter could be explained by a change in the transport mechanism, i.e., interstitial proton hopping to oxygen vacancy diffusion. ${ }^{13}$ However, it is not clear if this change, associated with the dehydration of the oxide, also induces a rearrangement of oxygen atoms resulting in a phase transition hidden by the insensitivity of X-rays to distinguish light-atom positions in the presence of heavy atoms.

Proton Conductivity Verification. The protonic transport nature of $\mathrm{BCZY}$ can be resolved from experiments on the $\mathrm{H} / \mathrm{D}$ isotopic effect. Figure 2 displays the variation of

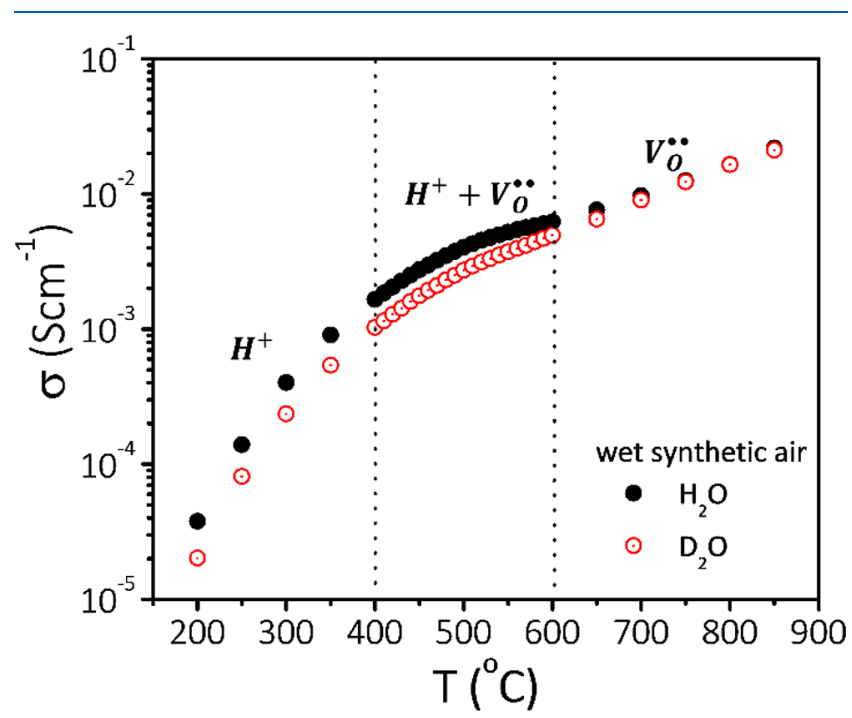

Figure 2. Isotopic effect on the conductivity in synthetic air with a water concentration of $\sim 2 \% \mathrm{H}_{2} \mathrm{O}$ or a heavy water concentration of $\sim 2 \% \mathrm{D}_{2} \mathrm{O}$ in the gas feed.

conductivity with temperature in air wet by $\mathrm{H}_{2} \mathrm{O}$ and $\mathrm{D}_{2} \mathrm{O}$. The H/D isotopic effect $\beta$ and protonic transport number $t_{\mathrm{H}^{+}}$ are defined as in ref 82

$$
\begin{aligned}
& \beta=\frac{\sigma_{\mathrm{H}^{+}}}{\sigma_{\mathrm{D}^{+}}} \\
& t_{\mathrm{H}^{+}}=\frac{\sigma_{\mathrm{H}^{+}}}{\sigma_{\text {total }}}=\frac{\sigma_{\mathrm{H}^{+}}}{\sigma_{\mathrm{H}^{+}}+\sigma_{\mathrm{V}_{\mathrm{O}}}+\sigma_{\mathrm{el}}}
\end{aligned}
$$

where $\sigma_{\mathrm{H}^{+}}, \sigma_{\mathrm{D}+}, \sigma_{\mathrm{V}_{\mathrm{o}}}$, and $\sigma_{\mathrm{el}}$ correspond to proton $\left(\mathrm{OH}^{\bullet}\right)$, deuterium $\left(\mathrm{OD}^{\bullet}\right)$, oxygen vacancies $\left(\mathrm{V}_{\mathrm{O}}^{\bullet \bullet}\right)$, and electronic conductivity, respectively. It was reported that the p-type electronic conductivity is present at high temperatures and wet oxidizing atmospheres; ${ }^{82,87-90}$ however, our discussion is focused to describe the ionic transport nature. Further boundary conditions are reasonably defined for those temperatures where oxygen vacancies are fully hydrated and the number of free oxygen vacancies is negligible, and those temperatures that support the complete dehydration of oxygen vacancies. Focusing mainly in the ionic part, ${ }^{15}$ three conductivity regions can be distinguished as follows (see Figure 2):

- Below $400{ }^{\circ} \mathrm{C}, \sigma\left(\mathrm{H}_{2} \mathrm{O}\right)>\sigma\left(\mathrm{D}_{2} \mathrm{O}\right)$, the sample is fully hydrated $\sigma_{\mathrm{H}^{+}} \gg \sigma_{\mathrm{V}_{\mathrm{o}}}$, and $t_{\mathrm{H}^{+}} \approx 1 . \beta$ takes values between 1.4 and 1.8 , which is indicative for proton conductivity, in agreement with those reported for Ricote et al. for $\mathrm{BaCe}_{0.9-x} \mathrm{Zr}_{x} \mathrm{Y}_{0.1} \mathrm{O}_{3-\delta}$ compounds. $^{82}$

- Above $700{ }^{\circ} \mathrm{C}, \sigma\left(\mathrm{H}_{2} \mathrm{O}\right)=\sigma\left(\mathrm{D}_{2} \mathrm{O}\right)$, the sample is completely dehydrated (see Figure 3 in ref 13 ), $\sigma_{\mathrm{H}^{+}} \ll$ $\sigma_{\mathrm{V}_{\mathrm{O}}}$, and electrical conductivity is independent of the (heavy) water content of the gas feed, so $\beta \approx 1$ and $t_{\mathrm{H}^{+}} \approx$ 0 . There is no protonic conductivity and the transport mechanism is dominated by oxygen vacancies.

- Between 400 and $600{ }^{\circ} \mathrm{C}$, oxygen vacancies are partially hydrated and $\sigma_{\text {total }} \approx \sigma_{\mathrm{H}^{+}}+\sigma_{\mathrm{V}_{\mathrm{o}}^{\circ}}$, which corresponds to mixed protonic and oxygen ionic conductivity. $\beta$ takes values between 1.2 and 1.4 and $t_{\mathrm{H}^{+}}<1$.

The slight difference between the conductivity indicated on Figure 1c and Figure 2 could be due to the shorter times between collection data for in situ experiments, which would produce an incomplete hydration/dehydration condition. The dwell time before simultaneous measurements was $30 \mathrm{~min}$; meanwhile the isotopic effect on impedance spectra were collected after 45 min.

The conductivity is also related to the hydrogen-diffusion coefficient $\left(D_{\mathrm{H}}\right)$, which depends on the jump distance $(l)$ and a relaxation frequency or characteristic time of residence $(\tau)$. These parameters can be estimated from QENS experiments. Figure 3a shows the effect of temperature on the QENS

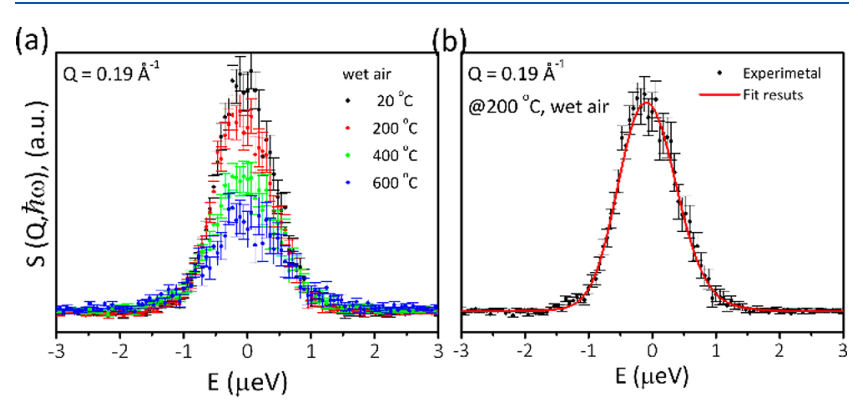

Figure 3. (a) Neutron scattering spectra, $S(Q, \hbar \omega)$ of BCZY at momentum transfer $Q=0.19 \AA^{-1}$. The inset compares the temperature effect on quasielastic dispersion. (b) Exemplary fit of a QENS spectrum using the CEM.

spectra of BCZY at the minimum $Q$ measured. With increasing temperature, the fraction of immobile protons $\left(f_{0}\right)$, not contributing to the diffusive dynamics, decreases and the width of the Lorentzian function increases, as a larger fraction of protons jump between oxygen sites and the residence time decreases. Figure $3 b$ shows an example of the fits achieved using the $\mathrm{CEM}^{65}$ and eq 3 : 


$$
\begin{aligned}
S(Q, \hbar \omega)= & {\left[f_{0} \delta(\hbar \omega)+\left(1-f_{0}\right) \frac{1}{\pi} \frac{\Gamma_{\mathrm{CE}}}{(\hbar \omega)^{2}+\Gamma_{\mathrm{CE}}{ }^{2}}\right] } \\
& \otimes R(Q, \hbar \omega)+B(Q)
\end{aligned}
$$

where $S(Q \hbar \omega)$ is the corrected dynamic structure factors obtained from fit with $\Gamma_{\mathrm{CE}}=\frac{1}{\tau}\left[1-\frac{\sin (Q l)}{\mathrm{Ql}}\right]$. Then, the proton diffusion coefficient is calculated from the above parameters as

$$
D_{\mathrm{H}}=\frac{l^{2}}{6 \tau}
$$

The $l$ was fixed to the average jump length of 3.4(1) A. This distance is comparable to the typical intraoctahedral oxygen distance (of $\sim 3.1 \AA$ ), and only the mean residence time was refined. At $25{ }^{\circ} \mathrm{C}$ the quasielastic intensity is so small that no reliable values for $\tau$ can be obtained. However, between 200 and $600{ }^{\circ} \mathrm{C}$ reasonable fits were obtained and the resulting parameters are shown in Table 1 , together with the proton

Table 1. Temperature-Dependent Fraction of Immobile Protons $f_{0}$ for an Average Jump Length of 3.4 $\AA$, Residence Time $\tau$, and Hydrogen Diffusion Coefficient $D_{H}$

$\begin{array}{cclc}T\left({ }^{\circ} \mathrm{C}\right) & f_{0} & \tau(\mathrm{ns}) & D_{\mathrm{H}}\left(\mathrm{cm}^{2} \mathrm{~s}^{-1}\right) \\ 200 & 0.75 & 0.9(4) & 2.1(9) \times 10^{-7} \\ 400 & 0.45 & 0.16(5) & 1.2(4) \times 10^{-6} \\ 600 & 0.50 & 0.06(3) & 3.3(1.6) \times 10^{-6}\end{array}$

diffusion coefficients derived from the mean residence times. The diffusion coefficients obtained here are in good agreement with those previously determined also using QENS in doped barium zirconates (e.g., for $\mathrm{BaZr}_{0.8} \mathrm{In}_{0.2} \mathrm{O}_{2.90}, D_{\mathrm{H}} \sim 2.8 \times 10^{-7}$ $\mathrm{cm}^{2} / \mathrm{s}$ at $277^{\circ} \mathrm{C}$, 55 and for $\mathrm{BaZr}_{0.85} \mathrm{Y}_{0.15} \mathrm{O}_{2.925}, D_{\mathrm{H}} \sim 2.5 \times 10^{-6}$ $\mathrm{cm}^{2} / \mathrm{s}$ at $\left.400{ }^{\circ} \mathrm{C}\right) .{ }^{91}$ Fitting the data shown in Table 1 to an Arrhenius law, we obtain an activation energy of 245 (30) meV. This is larger than values reported from other QENS studies by Noferini et al., which are in the range $40-120 \mathrm{meV},{ }^{55}$ or Braun et al. for $\mathrm{BaZr}_{0.9} \mathrm{Y}_{0.1} \mathrm{O}_{3-\delta}{ }^{92}$ Nevertheless, they are still below usual activation energies derived from IS measurements, which are usually in the range $300-600 \mathrm{meV},{ }^{92-94}$ or even QENS measurements on $\mathrm{Ba}\left[\mathrm{Ca}_{(1+x) / 3} \mathrm{Nb}_{(2-\mathrm{x}) / 3}\right] \mathrm{O}_{3-x / 2}$ mixed perovskites. ${ }^{95}$ As in most of the studied cases, when the diffusion coefficients obtained from QENS and EIS are compared, there is a noticeable difference of about 2 orders of magnitude. In the case of IS, a diffusion coefficient is obtained by applying the Nernst-Einstein relationship:

$$
D_{\sigma}=\frac{k_{\mathrm{b}} T}{e^{2}} \frac{V}{\left[\mathrm{OH}^{\bullet}\right]}
$$

where $k_{\mathrm{B}}, e, V$, and $\left[\mathrm{OH}^{\bullet}\right]$ correspond to Boltzmann constant, electron charge, unit-cell volume, and proton concentration on perovskite, respectively. ${ }^{46}$ Thus, at $400{ }^{\circ} \mathrm{C}$, we obtain a value $D_{\sigma}=7.2 \times 10^{-9} \mathrm{~cm}^{2} \mathrm{~s}^{-1}$, which can be compared with the value of $D_{\mathrm{H}}$ derived from QENS, $1.6 \times 10^{-6} \mathrm{~cm}^{2} \mathrm{~s}^{-1}$. Those differences are similar to those reported by other authors ${ }^{91,92}$ and are explained by the fact that they correspond to different diffusion mechanisms. The first one evaluates an effective conductivity diffusion at a macroscopic level, whereas QENS is sensitive to local diffusion processes involving the protons in the nanometer and nanosecond ranges.

Enhanced Structural Characterization. So far, the described results confirm that $\mathrm{BCZY}$ is a protonic conductor below $600{ }^{\circ} \mathrm{C}$ and that crystal structure and conductivity are correlated. Water incorporation causes XRD peak broadening and strain, and it induces lattice expansion. Conversely, lattice contraction and strain relief are due to dehydration. These behaviors are in agreement with our previous study on BCZY perovskites. ${ }^{13}$ Besides, the observed correlation between conductivity and lattice parameter, in particular, the kink below $525^{\circ} \mathrm{C}$, could be associated with a change of symmetry during sample dehydration. However, XRD is insensible to detect symmetry changes caused by the rearrangement of light atoms inside a heavy atom lattice like BCZY. Hence, ND is a key technique to overcome this hurdle. For instance, Malavasi et al. reported three phase transitions for lower $\mathrm{Zr}$-doping levels $(x=0.1$ and 0.2$)$ in $\mathrm{BaCe}_{0.85-x} \mathrm{Zr}_{x} \mathrm{Y}_{0.15} \mathrm{O}_{3-\delta}$ from monoclinic to orthorhombic to rhombohedral to cubic symmetry, between room temperature and $800{ }^{\circ} \mathrm{C}$ in air under static conditions. Samples with higher Zr-doping levels $(x=0.3$ and 0.4$)$ exhibited rhombohedral symmetry at room temperature and cubic symmetry above $520{ }^{\circ} \mathrm{C} .{ }^{54}$ Mather et al. reported phase transitions, octahedral tilting angles, deuterium sites, and $\mathrm{O}-\mathrm{D}$ distance for $\mathrm{BaZr}_{0.7} \mathrm{Ce}_{0.2} \mathrm{Y}_{0.1} \mathrm{O}_{3-\delta}$ perovskites by a combination of synchrotron $\mathrm{XRD}$ and $\mathrm{ND}$ at several temperatures. ${ }^{96}$ These authors reported that phase stability is also highly dependent on the hydration degree. $\mathrm{BaZr}_{0.7} \mathrm{Ce}_{0.2} \mathrm{Y}_{0.1} \mathrm{O}_{3-\delta}$ presents two transitions (orthorhombic to rhombohedral and then to cubic symmetry) between -188 and $+900{ }^{\circ} \mathrm{C}$ on the heating run at low vacuum, while the rhombohedral to cubic phase transition occurs below room temperature on the cooling run for the dehydrated sample. This behavior was also observed for other Ba-rich perovskites. For example, Knöchel et al. and Waidha et al. combined XRD and $\mathrm{ND}$ to evaluate the crystal structure of $\mathrm{Ba}(\mathrm{Fe}, \mathrm{Co}) \mathrm{O}_{3-\delta}$ mixed proton and electronic conductors with low and high water content. ${ }^{97,98}$ Therefore, the real structure of BCZY can be determined by combining XRD and ND. Figure 4 compares XRD and ND patterns of powders presaturated with $\mathrm{H}_{2} \mathrm{O}$ vapor at room temperature and the corresponding samples measured in air. Again, XRD results suggest BCZY adopting a cubic symmetry $P m \overline{3} m$ whereas the oxygen lattice obtained from ND pattern reveals a slight distortion of the perovskite oxygen octahedra leading to a rhombohedral symmetry $R \overline{3} c$. This result is in agreement with those reported for Malavasi et al. ${ }^{54}$ The phase transition between room temperature $R \overline{3} c$ and high temperature $P m \overline{3} m$ is related by intermediate symmetries, some of them could be compatible with the room temperature diffraction patterns. By using the tools from the Bilbao Crystallographic Server, ${ }^{99-101}$ we obtained the possible klassengleiche $(k)$ subgroups from the parent $P m \overline{3} m$ to evaluate the crystalline structure of the sample. The poor fitting results allowed us to discard the possibility of symmetry higher than $R \overline{3} c$ for the room temperatures.

Figure 5 presents the results of a simultaneous refinement of XRD and ND patterns of BCZY at 400 and $600{ }^{\circ} \mathrm{C}$ collected under ambient atmosphere. Table 2 summarizes the refined structural parameters. The oxygen occupation is $\sim 97 \%$, and the oxygen content $3-\delta \sim 2.9$, which is almost constant throughout the whole temperature range and in agreement with the $\mathrm{Y}^{3+}$ doping. The Wyckoff positions of the hydrogen atoms in BCZY are $36 \mathrm{f}$ and $12 \mathrm{~h}$ for $R \overline{3} c$ and $P m \overline{3} m$, respectively. ${ }^{96}$ The lattice parameters of the rhombohedral phase increase between 25 and $400{ }^{\circ} \mathrm{C}$. The short and long intraoctahedral $\mathrm{O}-\mathrm{O}$ distances increase from 3.052 to 3.061 and 3.068 to $3.073 \AA$, respectively. However, long intra- 


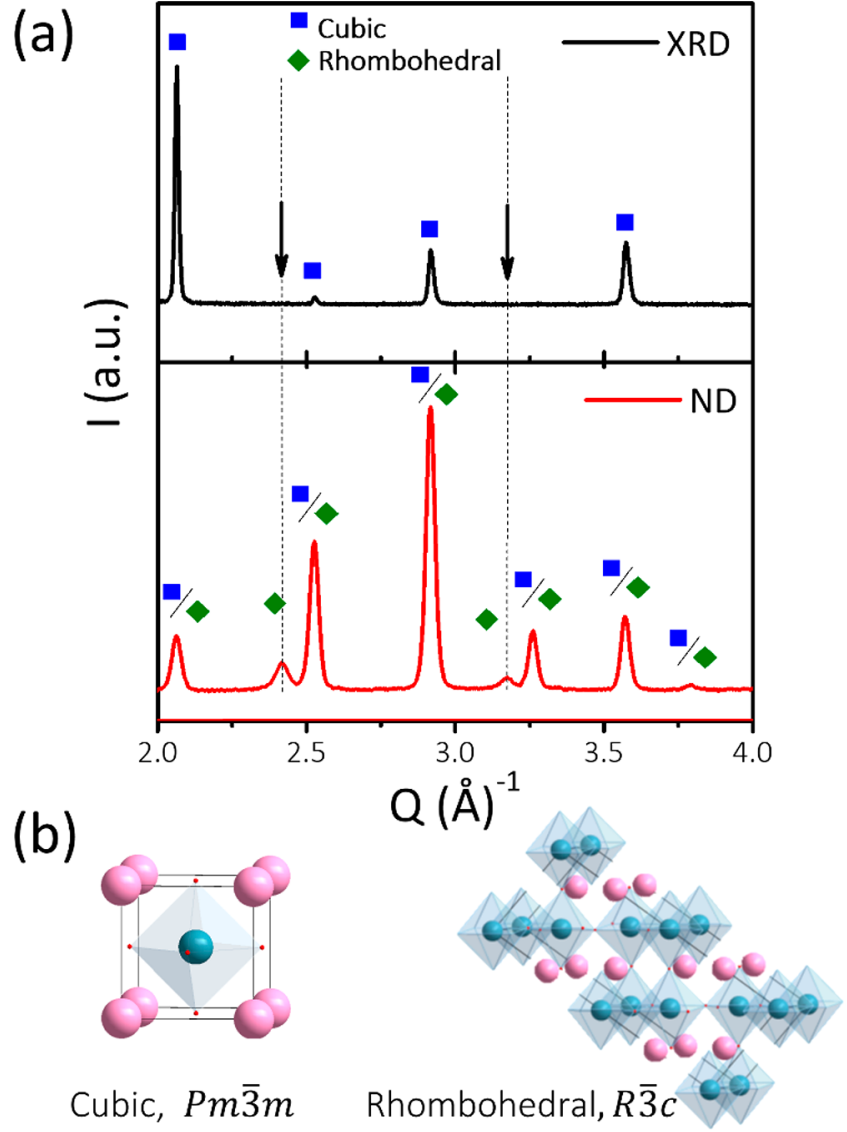

Figure 4. (a) Comparison between XRD and ND patterns of BCZY powder samples acquired at room temperature in air. (b) Cubic and rhombohedral crystal structures of BCYZ.

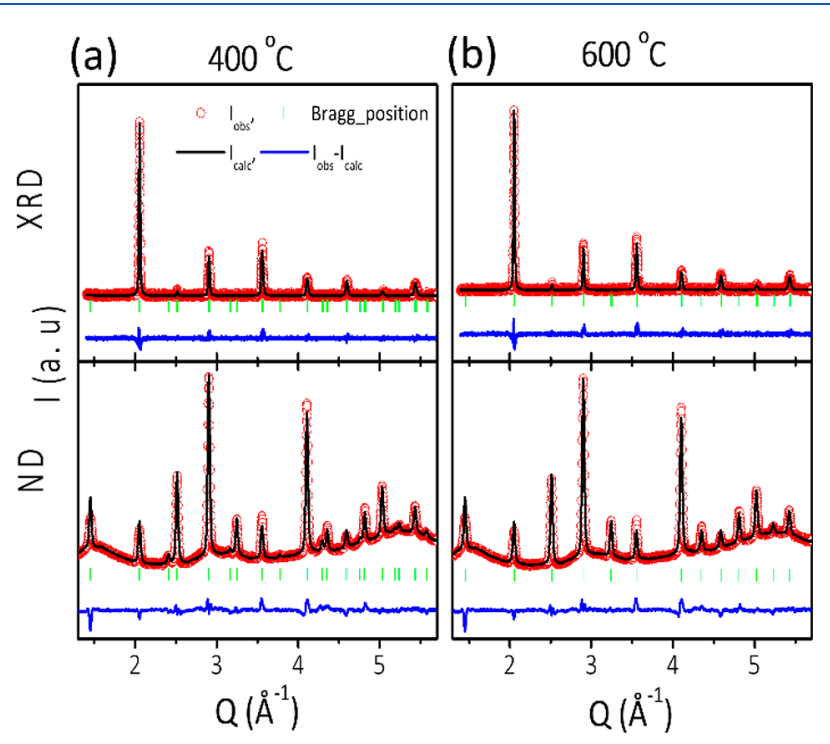

Figure 5. Simultaneous refinement of BCZY powder samples for XRD (above) and ND (below) patterns collected in air at (a) $400{ }^{\circ} \mathrm{C}$ fitted using rhombohedral symmetry and (b) at $600{ }^{\circ} \mathrm{C}$ with cubic structure.

octahedral O-O distances decrease from 4.605 to $4.554 \AA$ and the short ones increase from 4.032 to $4.109 \AA$. This effect indicates the loss of the octahedral tilt and, with it, the loss of the rhombohedral symmetry. BCZY presents a second-order phase transition from $R \overline{3} c$ to $P m \overline{3} m$ above $400{ }^{\circ} \mathrm{C}$. ${ }^{96}$
Basically, the phase transition is related to a crystallographic distortion induced by the hydration/dehydration process, which affects the lattice parameters, mass content, thermal expansion coefficient (TEC), and ionic transport properties. This phase transition influences the ionic transport mechanism, which is moderated by water under oxidizing and reducing atmospheres as observed by Mather et al. for $\mathrm{BaZr}_{0.7} \mathrm{Ce}_{0.2} \mathrm{Y}_{0.1} \mathrm{O}_{3-\delta}$ perovskites. ${ }^{96}$ In addition, the combined $\mathrm{XRD} / \mathrm{ND}$ analyses indicate that the $\mathrm{O}-\mathrm{O}$ distances of $\mathrm{BCZY}$ reach about $3.1 \AA$, which are comparable to those calculated by using QENS and CEM, thus demonstrating that hydrogen transport happens through interoctahedral $\mathrm{O}-\mathrm{O}$ jump diffusion.

The correlation between structural and dynamic information obtained from neutron techniques could give us insight into the hydrogen transfer mechanism. Density functional theory (DFT) calculations on Gd-doped ${ }^{102}$ and Y-doped ${ }^{103}$ $\mathrm{BaCeO}_{3-\delta}$ compounds suggest that interoctahedral hopping is favored by octahedral tilting, which shortens some of the $\mathrm{O}-$ $\mathrm{O}$ distances, from one apical oxygen site toward the next one on the next near-neighbor octahedron. Jeong et al. ${ }^{103}$ estimated from DFT, the energy barriers along different pathways for the proton migration in Y-doped $\mathrm{BaCeO}_{3}$, obtaining $0.45 \mathrm{eV}$ for intraoctahedral proton transfer and 0.22 $\mathrm{eV}$ for interoctahedral transfer. However, these energy barriers increase to $0.75-1.12 \mathrm{eV}$ and $0.40-0.45 \mathrm{eV}$ when two protons are considered for the calculations for intra- and interoctahedral hopping, respectively. Azad et al. ${ }^{52}$ suggests from ND studies on deuterated samples of $\mathrm{BaCe}_{0.4} \mathrm{Zr}_{0.4} \mathrm{Sc}_{0.2} \mathrm{O}_{2.90}$ that the proton hopping mainly involves the $\mathrm{O}$ interoctahedral sites through the shorter $\mathrm{O}-\mathrm{O}$ distance on the $\mathrm{BaO}$ planes (i.e., $\mathrm{O}$ apical), which is in agreement with those proposed by DFT calculations. $^{102,103}$ In this work, the different $\mathrm{O}-\mathrm{O}$ distances obtained for the rhombohedral structure are displayed in Figure 6a. This shows the shorter jump length distances for the intraoctahedral hydrogen transfer in comparison to the length distances for the interoctahedral one. In addition, nuclear density distributions calculated by the maximum entropy method $(\mathrm{MEM})^{67,68}$ are shown in Figure $6 \mathrm{c}$ for two parallel (012) planes: $\mathrm{Ba}-\mathrm{O}$ and $(\mathrm{CeZr}, \mathrm{Y})-\mathrm{O}$ (see planes indicated in Figure $6 \mathrm{~b})$. These figures symbolize the largest oxygen anisotropy on the $\mathrm{Ce}, \mathrm{Zr}, \mathrm{Y}-\mathrm{O}$ plane with respect to the $\mathrm{Ba}-$ $\mathrm{O}$ plane despite the structure being fitted with an isotropic model for an atomic Debye-Waller thermal displacements. This anisotropy stimulates proton hopping into the $\mathrm{O}$ intraoctahedral sites, in agreement with the QENS results. The combination of these techniques confirm the protonic nature of $\mathrm{BCZY}$ conduction below $600{ }^{\circ} \mathrm{C}$, and the intraoctahedra hydrogen transport through the perovskite. The main difference between BCZY and those discussed above is that in those cases, the perovskites present higher distorted structure with two crystallographic sites for $\mathrm{O}$.

Then, it is reasonable to expect that high symmetry of BCZY enhance the intraoctahedral hydrogen jump instead of interoctahedral.

\section{CONCLUSIONS}

Crystallographic and transport properties of BCZY were simultaneously studied in situ by S-XRD and IS, respectively. These results, in addition to the analysis of the isotopic effect $\mathrm{H} / \mathrm{D}$, indicate a strong correlation between crystallographic and electrochemical temperature-dependent properties, where protonic conductivity is the dominant transport mechanism 
Table 2. Temperature-Dependent Structural Parameters of BCZY Obtained from Simultaneous Refinements of XRD ${ }^{b}$ and $\mathrm{ND}^{c}$ Data by Using the Rietveld Method ${ }^{a}$

\begin{tabular}{|c|c|c|c|c|c|c|c|c|c|c|c|c|c|}
\hline \multirow[b]{2}{*}{$\begin{array}{c}T \\
\left({ }^{\circ} \mathrm{C}\right)\end{array}$} & \multirow[b]{2}{*}{$\begin{array}{l}\text { space } \\
\text { group }\end{array}$} & \multicolumn{3}{|c|}{ Wyckoff position } & \multicolumn{2}{|c|}{$\begin{array}{l}\text { crystallographic data } \\
\text { from oxygen }\end{array}$} & \multicolumn{3}{|c|}{$\begin{array}{l}\text { isotropic displacement parameter } \\
U_{\text {iso }}\left(\times 10^{2}\right)\left(\AA^{2}\right)\end{array}$} & \multirow[b]{2}{*}{$a(\AA)$} & \multirow[b]{2}{*}{$c(\AA)$} & \multirow[b]{2}{*}{$\begin{array}{l}V\left(\AA^{3}\right) / \text { unit } \\
\text { formula }\end{array}$} & \multirow[b]{2}{*}{$3-\delta$} \\
\hline & & $\mathrm{Ba}$ & $\mathrm{Ce}, \mathrm{Zr}, \mathrm{Y}$ & $\mathrm{O}$ & $x$ position & occupation $^{d}$ & $\mathrm{Ba}$ & $\mathrm{Ce}, \mathrm{Zr}, \mathrm{Y}$ & $\mathrm{O}$ & & & & \\
\hline 25 & $R \overline{3} c$ & $6 a$ & $6 \mathrm{~b}$ & $18 \mathrm{e}$ & $0.533(1)$ & $0.968(2)$ & $1.96(4)$ & $0.73(3)$ & $3.33(4)$ & $6.096(1)$ & $14.913(2)$ & $79.99(5)$ & $2.90(1)$ \\
\hline 200 & & & & & $0.531(1)$ & $0.954(2)$ & $1.85(5)$ & $0.37(4)$ & $2.73(4)$ & $6.107(1)$ & $14.947(2)$ & $80.42(6)$ & $2.86(1)$ \\
\hline 400 & & & & & $0.526(1)$ & $0.962(2)$ & $2.10(5)$ & $0.50(4)$ & $3.23(5)$ & $6.122(1)$ & $14.962(1)$ & $80.93(6)$ & $2.89(1)$ \\
\hline 600 & $P m \overline{3} m$ & $1 \mathrm{a}$ & $1 \mathrm{~b}$ & $3 c$ & 0.5 & $0.964(2)$ & $2.38(4)$ & $0.57(4)$ & $4.01(4)$ & & $2(1)$ & $81.29(1)$ & $2.89(1)$ \\
\hline
\end{tabular}

${ }^{a_{T}}$ The goodness of fit factors are higher with respect to the expected ones; however, they were tested by other crystallographic models as orthorhombic, tetragonal, etc. without any improvement. Therefore, other symmetries were discarded for the BCZY perovskite. ${ }^{b}$ The goodness of fit factors $R_{\mathrm{p}}, R_{\mathrm{wp}}$, and $\chi$ from XRD patterns takes values between 29.6 and $35.7 \%, 30.2$ and $34.6 \%$, and 1.59 and 1.83 , respectively. ${ }^{c}$ In the case of ND patterns, $R_{\mathrm{p}}, R_{\mathrm{wp}}$, and $\chi$ values are around $17.9-20.6 \%, 15.8-16.1 \%$, and $8.2-12.9$, respectively. ${ }^{d}$ The occupation of $\mathrm{Ba}$ and $(\mathrm{Ce}, \mathrm{Zr}, \mathrm{Y})$ sites were assumed as full (i.e., 1) while $\mathrm{O}$ occupations were adjusted.

a)

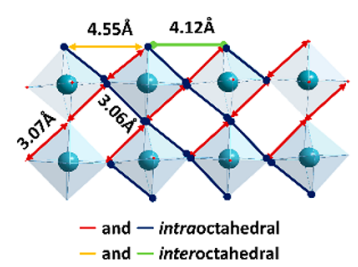

b)

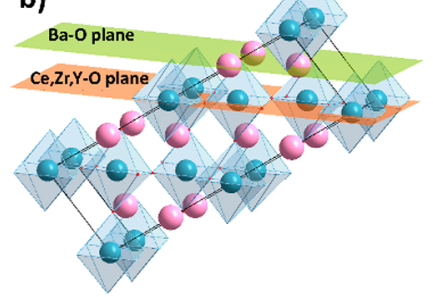

c)

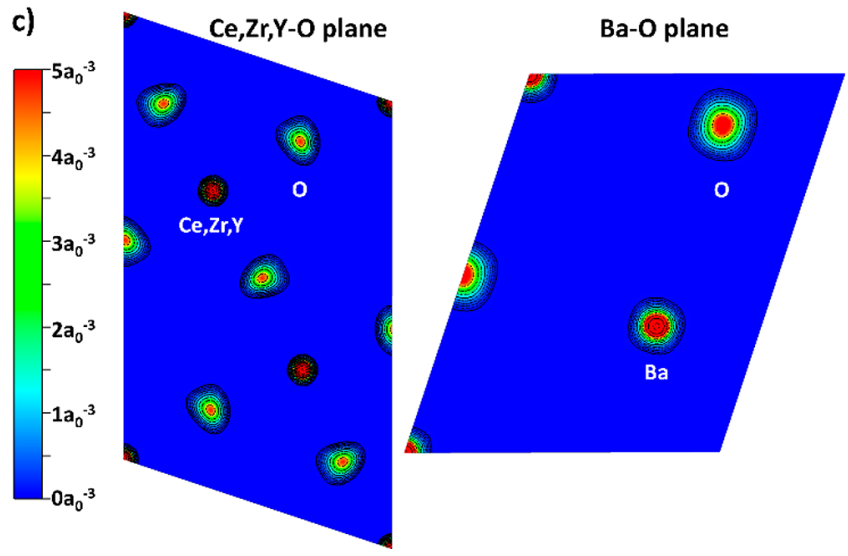

Figure 6. (a) Distances between oxygen sites on BCZY for rhombohedral symmetry at room temperature in air. (b) Rhombohedral crystal structure where slices on plane (012) were used to evaluate the $(\mathrm{Ce}, \mathrm{Zr}, \mathrm{Y})-\mathrm{O}$ and $\mathrm{Ba}-\mathrm{O}$ coordination spheres. (c) MEM nuclear density distributions on these planes with an isosurface level of $0.1 a_{0}^{-3}$ ( $a_{0}$ corresponds to the Bohr radii).

below $600{ }^{\circ} \mathrm{C}$. Then, the operation temperature range for $\mathrm{BCZY}$ to be used as proton conductor, e.g., in energy applications, was effectively determined in this work. The proton transport nature in the $\mathrm{BCZY}$ was also confirmed by QENS, which indicates self-diffusion by proton hopping between intraoctahedral oxygen sites with hydrogen jump distances of about $3.1 \AA$ and a self-diffusion coefficient of $9.4 \times$ $10^{-7} \mathrm{~cm}^{2} \mathrm{~s}^{-1}$ at $400{ }^{\circ} \mathrm{C}$. The strong correlation between the structure and transport below $600^{\circ} \mathrm{C}$ suggested that the BCZY structure is more complex than the single cubic phase observed by X-ray and electron diffraction techniques at room temperature. Complementary $\mathrm{XRD}$ and $\mathrm{ND}$ revealed a rhombohedral symmetry $R \overline{3} c$ between 25 and $400{ }^{\circ} \mathrm{C}$ that transforms into cubic with a $P m \overline{3} m$ space group at $600{ }^{\circ} \mathrm{C}$ once the sample dehydration is complete. The intraoctahedral oxygen distances reach about $3.1 \AA$, which are comparable to those calculated by QENS and shorter than the interoctahedral oxygen distance in the $\mathrm{BaO}$ plane (4.1-4.5 $\AA$ ). This is in agreement with a hydrogen self-diffusion mechanism, where hydrogen transfer mainly involves jumps between intraoctahedral oxygen instead of the typical interoctahedral transfer dominating in other more distorted perovskites. Characterization techniques based on neutrons resulted to be key to unveil the protonic nature of BCZY and can be expanded to other proton conducting ceramics for comparison with laboratory methods.

\section{ASSOCIATED CONTENT}

\section{Supporting Information}

The Supporting Information is available free of charge at https://pubs.acs.org/doi/10.1021/acsaem.9b02498.

Experimental details and a broad discussion for preliminary structural characterization; data acquisition system for simultaneous characterization (in situ crystallographic and conductivity study) (PDF)

\section{AUTHOR INFORMATION}

\section{Corresponding Author}

Juan F. Basbus - Centro Atómico Bariloche (CAB), Instituto de Nanociencia y Nanotecnología (INN) - CNEA - CONICET, S. C. de Bariloche, 8400 Rio Negro, Argentina; (1) orcid.org/ 0000-0002-6799-8421; Phone: +54 9294444 5100. ext 5325; Email: basbus@cab.cnea.gov.ar

\section{Authors}

Mauricio D. Arce - Centro Atómico Bariloche (CAB), Instituto de Nanociencia y Nanotecnología (INN) - CNEA CONICET, S. C. de Bariloche, 8400 Rio Negro, Argentina

Federico R. Napolitano - Centro Atomico Bariloche (CAB), Instituto de Nanociencia y Nanotecnología (INN) - CNEA CONICET, S. C. de Bariloche, 8400 Rio Negro, Argentina

Horacio E. Troiani - Centro Atómico Bariloche (CAB), Instituto de Nanociencia y Nanotecnologia (INN) - CNEA CONICET, S. C. de Bariloche, 8400 Rio Negro, Argentina

José A. Alonso - Instituto de Ciencia de Materiales de Madrid (CSIC), 28049 Madrid, Spain; 으orcid.org/0000-00015329-1225

Martín E. Saleta - Centro Atómico Bariloche (CAB), Instituto de Nanociencia y Nanotecnologia (INN) - CNEA CONICET, S. C. de Bariloche, 8400 Rio Negro, Argentina; Brazilian Synchrotron Light Laboratory (LNLS), Brazilian 
Center for Research in Energy and Materials (CNPEM), 13083-100 Campinas, Sao Paulo, Brazil

Miguel A. González - Institut Laue-Langevin (ILL), 38000 Grenoble, France

Gabriel J. Cuello - Institut Laue-Langevin (ILL), 38000 Grenoble, France

María T. Fernández-Díaz - Institut Laue-Langevin (ILL), 38000 Grenoble, France

Miguel Pardo Sainz - Instituto de Ciencia de Materiales de Aragón (ICMA), 50009 Zaragoza, Spain

Nikolaos Bonanos - Department of Energy Conversion and Storage, Technical University of Denmark, 4000 Roskilde, Denmark

Catalina E. Jimenez - Helmholtz-Zentrum Berlin (HZB), 14109 Berlin, Germany

Lars Giebeler - Leibniz-Institut für Festkörper- und Werkstoffforschung (IFW), 01069 Dresden, Germany; (1) orcid.org/0000-0002-6703-8447

Santiago J. A. Figueroa - Brazilian Synchrotron Light Laboratory (LNLS), Brazilian Center for Research in Energy and Materials (CNPEM), 13083-100 Campinas, Sao Paulo, Brazil; (1) orcid.org/0000-0003-2694-3050

Alberto Caneiro - Centro Atómico Bariloche ( $C A B)$, Instituto de Nanociencia y Nanotecnologia (INN) - CNEA CONICET, S. C. de Bariloche, 8400 Rio Negro, Argentina; YTEC, 1923 Berisso, Buenos Aires, Argentina

Adriana C. Serquis - Centro Atómico Bariloche ( $C A B)$, Instituto de Nanociencia y Nanotecnologia (INN) - CNEA CONICET, S. C. de Bariloche, 8400 Rio Negro, Argentina

Liliana V. Mogni - Centro Atómico Bariloche ( $C A B)$, Instituto de Nanociencia y Nanotecnologia (INN) - CNEA -

CONICET, S. C. de Bariloche, 8400 Rio Negro, Argentina

Complete contact information is available at:

https://pubs.acs.org/10.1021/acsaem.9b02498

\section{Notes}

The authors declare no competing financial interest.

\section{ACKNOWLEDGMENTS}

This work was supported by Agencia Nacional de Promoción de Ciencia y Tecnología (ANPCyT) PICT-2016-2965 and PICT2014-1849, CONICET PIP-2015-0565, LNLS (Brazil), under proposals 20150099 and 20170278, and ILL (France) under proposal 7-03-168. We thank to Laboratório Nacional de Nanotecnologia (LNNano) Campinas, Brazil, for supplying the impedance equipment, and B. Frick and F. Marchal from ILL for facilities provided during QENS experiments. L. Giebeler is grateful to the German Federal Ministry of Education and Research (BMBF) and the Argentinian Ministry of Science and Technology (MinCyT) for funding in the bilateral project DeFLeST (01DN14002). J. A. Alonso thanks the Spanish Ministry for Science, Innovation and Universities for funding the Project MAT2017-84496-R. J. F. Basbus is thankful for the Bec.Ar fellowship program and Laboratorio Argentino de Haces de Neutrones (LAHN).

\section{REFERENCES}

(1) Fabbri, E.; Pergolesi, D.; Traversa, E. Chem. Soc. Rev. 2010, 39, 4355.

(2) Kreuer, K. D. Proton ConductingOxides. Annu. Rev. Mater. Res. 2003, 33 (1), 333-359.

(3) Taniguchi, N.; Kuroha, T.; Nishimura, C.; Iijima, K. Characteristics of Novel $\mathrm{BaZr}_{0.4} \mathrm{Ce}_{0.4} \mathrm{In}_{0.2} \mathrm{O}_{3}$ Proton Conducting Ceramics and
Their Application to Hydrogen Sensors. Solid State Ionics 2005, 176 (39-40), 2979-2983.

(4) Phair, J. W.; Badwal, S. P. S. Review of Proton Conductors for Hydrogen Separation. Ionics 2006, 12, 103-115.

(5) Mukundan, R. Tritium Conductivity and Isotope Effect in Proton-Conducting Perovskites. J. Electrochem. Soc. 1999, 146 (6), 2184.

(6) Medvedev, D.; Murashkina, a.; Pikalova, E.; Demin, a.; Podias, a.; Tsiakaras, P. $\mathrm{BaCeO}_{3}$ : Materials Development, Properties and Application. Prog. Mater. Sci. 2014, 60, 72-129.

(7) Nasani, N.; Dias, P. a. N.; Saraiva, J. a.; Fagg, D. P. Synthesis and Conductivity of $\mathrm{Ba}(\mathrm{Ce}, \mathrm{Zr}, \mathrm{Y}) \mathrm{O}_{3-\delta}$ Electrolytes for PCFCs by New Nitrate-Free Combustion Method. Int. J. Hydrogen Energy 2013, 38 (20), 8461-8470.

(8) Sawant, P.; Varma, S.; Wani, B. N.; Bharadwaj, S. R. Synthesis, Stability and Conductivity of $\mathrm{BaCe}_{0.8-\mathrm{x}} \mathrm{Zr}_{\mathrm{x}} \mathrm{Y}_{0.2} \mathrm{O}_{3-\delta}$ as Electrolyte for Proton Conducting SOFC. Int. J. Hydrogen Energy 2012, 37 (4), 3848-3856.

(9) Zhao, L.; Tan, W.; Zhong, Q. The Chemical Stability and Conductivity Improvement of Protonic Conductor Ba$\mathrm{Ce}_{0.8-\mathrm{x}} \mathrm{Zr}_{\mathrm{x}} \mathrm{Y}_{0.2} \mathrm{O}_{3-\mathrm{d} .}$. Ionics 2013, 19 (12), 1745-1750.

(10) Guo, Y.; Lin, Y.; Ran, R.; Shao, Z. Zirconium Doping Effect on the Performance of Proton-Conducting. J. Power Sources 2009, 193, 400-407.

(11) Barison, S.; Battagliarin, M.; Cavallin, T.; Doubova, L.; Fabrizio, M.; Mortalò, C.; Boldrini, S.; Malavasi, L.; Gerbasi, R. High Conductivity and Chemical Stability of $\mathrm{BaCe}_{1-\mathrm{x}-\mathrm{y}} \mathrm{Zr}_{\mathrm{x}} \mathrm{Y}_{\mathrm{y}} \mathrm{O}_{3-\delta}$ Proton Conductors Prepared by a Sol-Gel Method. J. Mater. Chem. 2008, 18 (42), 5120.

(12) Lagaeva, J.; Medvedev, D.; Demin, A.; Tsiakaras, P. Insights on Thermal and Transport Features of $\mathrm{BaCe}_{0.8-\mathrm{x}} \mathrm{Zr}_{\mathrm{x}} \mathrm{Y}_{0.2} \mathrm{O}_{3-\delta}$ ProtonConducting Materials. J. Power Sources 2015, 278, 436-444.

(13) Basbus, J. F.; Arce, M. D.; Prado, F. D.; Caneiro, A.; Mogni, L. V. A High Temperature Study on Thermodynamic, Thermal Expansion and Electrical Properties of $\mathrm{BaCe}_{0.4} \mathrm{Zr}_{0.4} \mathrm{Y}_{0.2} \mathrm{O}_{3-\delta}$ Proton Conductor. J. Power Sources 2016, 329, 262-267.

(14) Nasani, N.; Ramasamy, D.; Mikhalev, S.; Kovalevsky, A. V.; Fagg, D. P. Fabrication and Electrochemical Performance of a Stable, Anode Cell. J. Power Sources 2015, 278, 582-589.

(15) Basbus, J.; Arce, M.; Troiani, H.; Su, Q.; Wang, H.; Caneiro, A.; Mogni, L. Study of $\mathrm{BaCe}_{0.4} \mathrm{Zr}_{0.4} \mathrm{Y}_{0.2} \mathrm{O}_{3-\delta} / \mathrm{BaCe}_{0.8} \mathrm{Pr}_{0.2} \mathrm{O}_{3-\delta}$ (BCZY/ BCP) Bilayer Membrane for Protonic Conductor Solid Oxide Fuel Cells (PC-SOFC). Int. J. Hydrogen Energy 2020, 45, 5481.

(16) Peterson, V. K.; Papadakis, C. M. Functional Materials Analysis Using in Situ and in Operando X-Ray and Neutron Scattering. IUCrJ 2015, 2 (2), 292-304.

(17) Gallo, E.; Glatzel, P. Valence to Core X-Ray Emission Spectroscopy. Adv. Mater. 2014, 26 (46), 7730-7746.

(18) Mueller, D. N.; Machala, M. L.; Bluhm, H.; Chueh, W. C. Redox Activity of Surface Oxygen Anions in Oxygen-Deficient Perovskite Oxides during Electrochemical Reactions. Nat. Commun. 2015, 6 (1), 6097.

(19) Brightman, E.; Maher, R.; Offer, G. J.; Duboviks, V.; Heck, C.; Cohen, L. F.; Brandon, N. P. Designing a Miniaturised Heated Stage for in Situ Optical Measurements of Solid Oxide Fuel Cell Electrode Surfaces, and Probing the Oxidation of Solid Oxide Fuel Cell Anodes Using in Situ Raman Spectroscopy. Rev. Sci. Instrum. 2012, 83 (5), 053707.

(20) Shen, Y.; Pedersen, E. E.; Christensen, M.; Iversen, B. B. An Electrochemical Cell for in Operando Studies of Lithium/Sodium Batteries Using a Conventional x-Ray Powder Diffractometer. Rev. Sci. Instrum. 2014, 85 (10), 104103.

(21) Hess, M.; Sasaki, T.; Villevieille, C.; Novák, P. Combined Operando X-Ray Diffraction-Electrochemical Impedance Spectroscopy Detecting Solid Solution Reactions of LiFePO4 in Batteries. Nat. Commun. 2015, 6 (1), 8169.

(22) Talaie, E.; Bonnick, P.; Sun, X.; Pang, Q.; Liang, X.; Nazar, L. F. Methods and Protocols for Electrochemical Energy Storage Materials Research. Chem. Mater. 2017, 29 (1), 90-105. 
(23) Liu, C.; Brant, W. R.; Younesi, R.; Dong, Y.; Edström, K.; Gustafsson, T.; Zhu, J. Towards an Understanding of $\mathrm{Li}_{2} \mathrm{O}_{2}$ Evolution in $\mathrm{Li}-\mathrm{O}_{2}$ Batteries: An In Operando Synchrotron X-Ray Diffraction Study. ChemSusChem 2017, 10 (7), 1592-1599.

(24) Gustafsson, T.; Thomas, J. O.; Koksbang, R.; Farrington, G. C. The Polymer Battery as an Environment for in Situ X-Ray Diffraction Studies of Solid-State Electrochemical Processes. Electrochim. Acta 1992, 37 (9), 1639-1643.

(25) Pietsch, P.; Hess, M.; Ludwig, W.; Eller, J.; Wood, V. Combining Operando Synchrotron X-Ray Tomographic Microscopy and Scanning X-Ray Diffraction to Study Lithium Ion Batteries. Sci. Rep. 2016, 6 (1), 27994.

(26) Nelson, J.; Misra, S.; Yang, Y.; Jackson, A.; Liu, Y.; Wang, H.; Dai, H.; Andrews, J. C.; Cui, Y.; Toney, M. F. In Operando X-Ray Diffraction and Transmission X-Ray Microscopy of Lithium Sulfur Batteries. J. Am. Chem. Soc. 2012, 134 (14), 6337-6343.

(27) Goonetilleke, D.; Pramudita, J. C.; Hagan, M.; Al Bahri, O. K.; Pang, W. K.; Peterson, V. K.; Groot, J.; Berg, H.; Sharma, N. Correlating Cycling History with Structural Evolution in Commercial 26650 Batteries Using in Operando Neutron Powder Diffraction. J. Power Sources 2017, 343, 446-457.

(28) Nazer, N. S.; Denys, R. V.; Yartys, V. A.; Hu, W.-K.; Latroche, M.; Cuevas, F.; Hauback, B. C.; Henry, P. F.; Arnberg, L. In Operando Neutron Diffraction Study of $\mathrm{LaNdMgNi}_{9} \mathrm{H}_{13}$ as a Metal Hydride Battery Anode. J. Power Sources 2017, 343, 502-512.

(29) Harks, P. P. R. M. L.; Mulder, F. M.; Notten, P. H. L. In Situ Methods for Li-Ion Battery Research: A Review of Recent Developments. J. Power Sources 2015, 288, 92-105.

(30) Herklotz, M.; Weiß, J.; Ahrens, E.; Yavuz, M.; Mereacre, L.; Kiziltas-Yavuz, N.; Dräger, C.; Ehrenberg, H.; Eckert, J.; Fauth, F. A Novel High-Throughput Setup for in Situ Powder Diffraction on Coin Cell Batteries. J. Appl. Crystallogr. 2016, 49 (1), 340-345.

(31) Gross, T.; Giebeler, L.; Hess, C. Novel in Situ Cell for Raman Diagnostics of Lithium-Ion Batteries. Rev. Sci. Instrum. 2013, 84 (7), 073109.

(32) Dolotko, O.; Senyshyn, A.; Mühlbauer, M. J.; Nikolowski, K.; Ehrenberg, H. Understanding Structural Changes in NMC Li-Ion Cells by in Situ Neutron Diffraction. J. Power Sources 2014, 255, 197203.

(33) Volkov, S.; Vonk, V.; Khorshidi, N.; Franz, D.; Kubicek, M.; Kilic, V.; Felici, R.; Huber, T. M.; Navickas, E.; Rupp, G. M. Operando X-Ray Investigation of Electrode/Electrolyte Interfaces in Model Solid Oxide Fuel Cells. Chem. Mater. 2016, 28 (11), 37273733.

(34) Matsui, T.; Eguchi, K.; Furukawa, T.; Okanishi, T.; Muroyama, H.; Eguchi, K. In Operando Raman Spectroscopy Study on Oxygen Chemical Potential Change in Ni-SDC Cermet Anode for Solid Oxide Fuel Cells. J. Electrochem. Soc. 2016, 163 (10), F1146-F1150.

(35) Duboviks, V.; Maher, R. C.; Offer, G.; Cohen, L. F.; Brandon, N. P. In-Operando Raman Spectroscopy Study of Passivation Effects on Ni-CGO Electrodes in $\mathrm{CO}_{2}$ Electrolysis Conditions. ECS Trans. 2013, 57 (1), 3111-3117.

(36) Zhang, C.; Grass, M. E.; McDaniel, A. H.; DeCaluwe, S. C.; Gabaly, F. El; Liu, Z.; McCarty, K. F.; Farrow, R. L.; Linne, M. A.; Hussain, Z. Measuring Fundamental Properties in Operating Solid Oxide Electrochemical Cells by Using in Situ X-Ray Photoelectron Spectroscopy. Nat. Mater. 2010, 9 (11), 944-949.

(37) Kirtley, J. D.; Halat, D. M.; McIntyre, M. D.; Eigenbrodt, B. C.; Walker, R. A. High-Temperature "Spectrochronopotentiometry": Correlating Electrochemical Performance with In Situ Raman Spectroscopy in Solid Oxide Fuel Cells. Anal. Chem. 2012, 84 (22), 9745-9753.

(38) Yildiz, B.; Myers, D. J.; Carter, J. D.; Chang, K.-C.; You, H. In Situ X-Ray and Electrochemical Studies of Solid Oxide Fuel Cell/ Electrolyzer Oxygen Electrodes. In Advances in Solid Oxide Fuel Cells III; John Wiley \& Sons, Inc.: Hoboken, NJ, USA, 2009; pp 153-164, DOI: 10.1002/9780470339534.ch15.
(39) Pomfret, M. B.; Owrutsky, J. C.; Walker, R. A. In Situ Studies of Fuel Oxidation in Solid Oxide Fuel Cells. Anal. Chem. 2007, 79 (6), 2367-2372.

(40) Topsøe, H. Developments in Operando Studies and in Situ Characterization of Heterogeneous Catalysts. J. Catal. 2003, 216 (12), 155-164.

(41) Weckhuysen, B. M. Studying Birth, Life and Death of Catalytic Solids with Operando Spectroscopy. Natl. Sci. Rev. 2015, 2 (2), 147149.

(42) Melke, J.; Schoekel, A.; Dixon, D.; Cremers, C.; Ramaker, D. E.; Roth, C. Ethanol Oxidation on Carbon-Supported Pt, PtRu, and PtSn Catalysts Studied by Operando X-Ray Absorption Spectroscopy. J. Phys. Chem. C 2010, 114 (13), 5914-5925.

(43) Colomban, P.; Slodczyk, A. The Structural and Dynamics Neutron Study of Proton Conductors: Difficulties and Improvement Procedures in Protonated Perovskite. Eur. Phys. J.: Spec. Top. 2012, 213 (1), 171-193.

(44) Malikova, N.; Loong, C.-K.; Zanotti, J.-M.; Fernandez-Alonso, F. Proton-Containing Yttrium-Doped Barium Cerate: A Simultaneous Structural and Dynamic Study by Neutron Scattering. J. Phys. Chem. C 2007, 111 (17), 6574-6580.

(45) Colomban, P.; Zaafrani, O.; Slodczyk, A. Proton Content and Nature in Perovskite Ceramic Membranes for Medium Temperature Fuel Cells and Electrolysers. Membranes (Basel, Switz.) 2012, 2 (4), 493-509.

(46) Chen, Q.; Banyte, J.; Zhang, X.; Embs, J. P.; Braun, A. Proton Diffusivity in Spark Plasma Sintered $\mathrm{BaCe}_{0.8} \mathrm{Y}_{0.2} \mathrm{O}_{3-\delta}$ : In-Situ Combination of Quasi-Elastic Neutron Scattering and Impedance Spectroscopy. Solid State Ionics 2013, 252, 2-6.

(47) Karlsson, M. Proton Dynamics in Oxides: Insight into the Mechanics of Proton Conduction from Quasielastic Neutron Scattering. Phys. Chem. Chem. Phys. 2015, 17 (1), 26-38.

(48) Noferini, D.; Koza, M. M.; Karlsson, M. Localized Proton Motions in Acceptor-Doped Barium Zirconates. J. Phys. Chem. C 2017, 121, 7088.

(49) Slodczyk, A.; Colomban, P.; Malikova, N.; Zaafrani, O.; Longeville, S.; Zanotti, J.-M.; Lacroix, O.; Sala, B. Bulk Protons in Anhydrous Perovskites-Neutron Scattering Studies. Solid State Ionics 2013, 252, 7-11.

(50) Alonso, J. A.; Martínez-Lope, M. J.; Aguadero, A.; Daza, L. Neutron Powder Diffraction as a Characterization Tool of Solid Oxide Fuel Cell Materials. Prog. Solid State Chem. 2008, 36 (1-2), 134-150.

(51) Tamimi, M. A.; McIntosh, S. High Temperature in Situ Neutron Powder Diffraction of Oxides. J. Mater. Chem. A 2014, 2 (17), 6015-6026.

(52) Azad, A. K.; Irvine, J. T. S. Location of Deuterium Positions in the Proton-Conducting Perovskite $\mathrm{BaCe}_{0.4} \mathrm{Zr}_{0.4} \mathrm{Sc}_{0.2} \mathrm{O}_{2.90} \mathrm{x} \mathrm{D}_{2} \mathrm{O}$ by Neutron Powder Diffraction. Chem. Mater. 2009, 21 (2), 215-222.

(53) Malavasi, L.; Ritter, C.; Chiodelli, G. Correlation between Thermal Properties, Electrical Conductivity, and Crystal Structure in the $\mathrm{BaCe}_{0.80} \mathrm{Y}_{0.20} \mathrm{O}_{2.9}$ Proton Conductor. Chem. Mater. 2008, 20 (6), 2343-2351.

(54) Malavasi, L.; Tealdi, C.; Ritter, C.; Pomjakushin, V.; Gozzo, F.; Diaz-Fernandez, Y. Combined Neutron and Synchrotron X-Ray Diffraction Investigation of the $\mathrm{BaCe}_{0.85-\mathrm{x}} \mathrm{Zr}_{\mathrm{x}} \mathrm{Y}_{0.15} \mathrm{O}_{3-\delta}(0.1 \leq x \leq 0.4)$ Proton Conductors. Chem. Mater. 2011, 23 (5), 1323-1330.

(55) Noferini, D.; Frick, B.; Koza, M. M.; Karlsson, M. Proton Jump Diffusion Dynamics in Hydrated Barium Zirconates Studied by HighResolution Neutron Backscattering Spectroscopy. J. Mater. Chem. A 2018, 6 (17), 7538-7546.

(56) Tolentino, H. C. N.; Ramos, A. Y.; Alves, M. C. M.; Barrea, R. A.; Tamura, E.; Cezar, J. C.; Watanabe, N. A 2.3 to $25 \mathrm{KeV}$ XAS Beamline at LNLS. J. Synchrotron Radiat. 2001, 8 (3), 1040-1046.

(57) Ravel, B.; Newville, M. ATHENA, ARTEMIS, HEPHAESTUS: Data Analysis for X-Ray Absorption Spectroscopy Using IFEFFIT. J. Synchrotron Radiat. 2005, 12 (4), 537-541. 
(58) Zabinsky, S. I.; Rehr, J. J.; Ankudinov, A.; Albers, R. C.; Eller, M. J. Multiple-Scattering Calculations of $\mathrm{x}$-Ray-Absorption Spectra. Phys. Rev. B: Condens. Matter Mater. Phys. 1995, 52 (4), 2995-3009.

(59) Napolitano, F.; Montenegro-Hernández, A.; Basbus, J. F.; Arce, M. D.; Mogni, L. V.; Serquis, A. Correlation Studies of Electrochemical and Crystallographic Properties on SOFC and Soec Related Materials By Simultaneous EIS and XRD In-Operando Measurements. 229th ECS Meeting; 2016; p I02.

(60) Ferreira, F. F.; Granado, E.; Carvalho, W.; Kycia, S. W.; Bruno, D.; Droppa, R. X-Ray Powder Diffraction Beamline at D10B of LNLS: Application to the $\mathrm{Ba}_{2} \mathrm{FeReO}_{6}$ Double Perovskite. J. Synchrotron Radiat. 2006, 13 (Pt 1), 46-53.

(61) Rodríguez-Carvajal, J. Recent Advances in Magnetic Structure Determination by Neutron Powder Diffraction. Phys. B 1993, 192 $(1-2), 55-69$.

(62) Finger, L. W.; Cox, D. E.; Jephcoat, A. P. A Correction for Powder Diffraction Peak Asymmetry Due to Axial Divergence. J. Appl. Crystallogr. 1994, 27 (6), 892-900.

(63) Frick, B.; Combet, J.; van Eijck, L. New Possibilities with Inelastic Fixed Window Scans and Linear Motor Doppler Drives on High Resolution Neutron Backscattering Spectrometers. Nucl. Instrum. Methods Phys. Res., Sect. A 2012, 669, 7-13.

(64) Richard, D.; Ferrand, M.; Kearley, G. J. Analysis and Visualisation of Neutron-Scattering Data. J. Neutron Res. 1996, 4 (1), 33-39.

(65) Chudley, C. T.; Elliott, R. J. Neutron Scattering from a Liquid on a Jump Diffusion Model. Proc. Phys. Soc., London 1961, 77 (2), $353-361$.

(66) Momma, K.; Ikeda, T.; Belik, A. A.; Izumi, F. Dysnomia, a Computer Program for Maximum-Entropy Method (MEM) Analysis and Its Performance in the MEM-Based Pattern Fitting. Powder Diffr. 2013, 28 (3), 184-193.

(67) Itoh, T.; Shirasaki, S.; Fujie, Y.; Kitamura, N.; Idemoto, Y.; Osaka, K.; Ofuchi, H.; Hirayama, S.; Honma, T.; Hirosawa, I. Study of Charge Density and Crystal Structure of $\left(\mathrm{La}_{0.75} \mathrm{Sr}_{0.25}\right) \mathrm{MnO}_{3.00}$ and $\left(\mathrm{Ba}_{0.5} \mathrm{Sr}_{0.5}\right)\left(\mathrm{Co}_{0.8} \mathrm{Fe}_{0.2}\right) \mathrm{O}_{2.33-\delta}$ at $500-900 \mathrm{~K}$ by in Situ Synchrotron XRay Diffraction. J. Alloys Compd. 2010, 491 (1-2), 527-535.

(68) Fujii, K.; Shimada, K.; Yashima, M. Crystal-Structure and Electron-Density Analyses of the Perovskite-Type Oxynitrides $\mathrm{BaNbO}_{2} \mathrm{~N}$ and $\mathrm{SrNbO}_{2} \mathrm{~N}$ through Synchrotron X-Ray Powder Diffraction. J. Ceram. Soc. Jpn. 2017, 125 (11), 808-810.

(69) Takata, M.; Nishibori, E.; Sakata, M. Charge Density Studies Utilizing Powder Diffraction and MEM. Exploring of High $T_{c}$ Superconductors, $\mathrm{C}_{60}$ Superconductors and Manganites. Z. Kristallogr. - Cryst. Mater. 2001, 216 (2), 71-86.

(70) Sakata, M.; Uno, T.; Takata, M.; Howard, C. J. MaximumEntropy-Method Analysis of Neutron Diffraction Data. J. Appl. Crystallogr. 1993, 26 (2), 159-165.

(71) Catelani, I. B.; Dias, G. S.; Santos, I. A.; Guo, R.; Bhalla, A. S.; Cótica, L. F. Maximum Entropy Method Applied in the Experimental Visualization of Electron Density Distributions in $\mathrm{BiFeO}_{3}$. Integr. Ferroelectr. 2015, 166 (1), 168-174.

(72) Yashima, M. Structural Disorder, Diffusion Pathway of Mobile Oxide Ions, and Crystal Structure. Perovskite-Type Oxides and Related Materials; Springer: Berlin, 2009; pp 117-145,.

(73) Igawa, N.; Kodama, K.; Birumachi, A.; Taguchi, T. Nuclear and Electron Density Distributions of $\mathrm{LiMn}_{2} \mathrm{O}_{4}$ Analyzed by Combination of Rietveld/Maximum Entropy Method. e-J. Surf. Sci. Nanotechnol. 2015, 13, 247-252.

(74) Ito, T.; Nagasaki, T.; Iwasaki, K.; Yoshino, M.; Matsui, T.; Igawa, N.; Ishii, Y. The Determination of Deuteron Site in $\mathrm{SrZr}_{0.95} \mathrm{Sc}_{0.05} \mathrm{O}_{3-\alpha}$ by Neutron Powder Diffraction. Solid State Ionics 2006, 177 (26-32), 2353-2356.

(75) Momma, K.; Izumi, F. VESTA 3 for Three-Dimensional Visualization of Crystal, Volumetric and Morphology Data. J. Appl. Crystallogr. 2011, 44 (6), 1272-1276.

(76) Di Bartolomeo, E.; D’Epifanio, A.; Pugnalini, C.; Giannici, F.; Longo, A.; Martorana, A.; Licoccia, S. Structural Analysis, Phase Stability and Electrochemical Characterization of $\mathrm{Nb}$ Doped
$\mathrm{BaCe}_{0.9} \mathrm{Y}_{0.1} \mathrm{O}_{3-\mathrm{x}}$ Electrolyte for IT-SOFCs. J. Power Sources 2012, 199, 201-206.

(77) Giannici, F.; Shirpour, M.; Longo, A.; Martorana, A.; Merkle, R.; Maier, J. Long-Range and Short-Range Structure of ProtonConducting $\mathrm{Y}: \mathrm{BaZrO}_{3}$. Chem. Mater. 2011, 23 (11), 2994-3002.

(78) Wu, J.; Webb, S. M.; Brennan, S.; Haile, S. M. Dopant Site Selectivity in $\mathrm{BaCe}_{0.85} \mathrm{M}_{0.15} \mathrm{O}_{3-\delta}$ by Extended $\mathrm{x}$-Ray Absorption Fine Structure. J. Appl. Phys. 2005, 97 (5), 054101.

(79) Uarth Fassbender, R.; Strelow Lilge, T.; Cava, S.; Andrés, J.; Fernando da Silva, L.; Roberto Mastelaro, V.; Longo, E.; Lucio Moreira, M. Fingerprints of Short-Range and Long-Range Structure in $\mathrm{BaZr}_{1-\mathrm{x}} \mathrm{Hf}_{\mathrm{x}} \mathrm{O}_{3}$ Solid Solutions: An Experimental and Theoretical Study. Phys. Chem. Chem. Phys. 2015, 17 (17), 11341-11349.

(80) Giannici, F.; Longo, A.; Balerna, A.; Kreuer, K.-D.; Martorana, A. Proton Dynamics in In:BaZrO${ }_{3}$ : Insights on the Atomic and Electronic Structure from X-Ray Absorption Spectroscopy. Chem. Mater. 2009, 21 (13), 2641-2649.

(81) Medvedev, D. A.; Lyagaeva, J. G.; Gorbova, E. V.; Demin, A. K. Progress in Materials Science Advanced Materials for SOFC Application: Strategies for the Development of Highly Conductive and Stable Solid Oxide Proton Electrolytes. Prog. Mater. Sci. 2016, 75, $38-79$.

(82) Ricote, S.; Bonanos, N.; Caboche, G. Water Vapour Solubility and Conductivity Study of the Proton Conductor Ba$\mathrm{Ce}_{(0.9-\mathrm{x})} \mathrm{Zr}_{\mathrm{x}} \mathrm{Y}_{0.1} \mathrm{O}_{(3-\delta)}$. Solid State Ionics 2009, 180 (14-16), 990-997.

(83) Duval, S. B. C.; Holtappels, P.; Vogt, U. F.; Stimming, U.; Graule, T. Characterisation of $\mathrm{BaZr}_{0.9} \mathrm{Y}_{0.1} \mathrm{O}_{3-\delta}$ Prepared by Three Different Synthesis Methods: Study of the Sinterability and the Conductivity. Fuel Cells 2009, 9 (5), 613-621.

(84) Ricote, S.; Bonanos, N.; Wang, H. J.; Boukamp, B. A. Conductivity Study of Dense $\mathrm{BaZr}_{0.9} \mathrm{Y}_{0.1} \mathrm{O}_{3-\delta}$ Obtained by Spark Plasma Sintering. Solid State Ionics 2012, 213, 36-41.

(85) Impedance Spectroscopy; Barsoukov, E., Macdonald, J. R., Eds., John Wiley \& Sons, Inc.: Hoboken, NJ, USA, 2005; DOI: 10.1002/ 0471716243.

(86) Pergolesi, D.; Fabbri, E.; D’Epifanio, A.; Di Bartolomeo, E.; Tebano, A.; Sanna, S.; Licoccia, S.; Balestrino, G.; Traversa, E. High Proton Conduction in Grain-Boundary-Free Yttrium-Doped Barium Zirconate Films Grown by Pulsed Laser Deposition. Nat. Mater. 2010, 9 (10), 846-852.

(87) Bonanos, N.; Poulsen, F. W. Considerations of Defect Equilibria in High Temperature Proton-Conducting Cerates. J. Mater. Chem. 1999, 9 (2), 431-434.

(88) Song, S.; Wachsman, E. D.; Dorris, S. E.; Balachandran, U. Defect Chemistry Modeling of High-Temperature Proton-Conducting Cerates. Solid State Ionics 2002, 149 (1-2), 1-10.

(89) Heras-Juaristi, G.; Pérez-Coll, D.; Mather, G. C. Temperature Dependence of Partial Conductivities of the $\mathrm{BaZr}_{0.7} \mathrm{Ce}_{0.2} \mathrm{Y}_{0.1} \mathrm{O}_{3-\delta}$ Proton Conductor. J. Power Sources 2017, 364, 52-60.

(90) Bonanos, N. Oxide-Based Protonic Conductors: Point Defects and Transport Properties. Solid State Ionics 2001, 145 (1-4), 265274.

(91) Groß, B.; Beck, C.; Meyer, F.; Krajewski, T.; Hempelmann, R.; Altgeld, $\mathrm{H}$. BaZr ${ }_{0.85} \mathrm{Me}_{0.15} \mathrm{O}_{2.925}(\mathrm{Me}=\mathrm{Y}$, In and Ga): Crystal Growth, High-Resolution Transmission Electron Microscopy, High-Temperature X-Ray Diffraction and Neutron Scattering Experiments. Solid State Ionics 2001, 145 (1-4), 325-331.

(92) Braun, A.; Duval, S.; Ried, P.; Embs, J.; Juranyi, F.; Strässle, T.; Stimming, U.; Hempelmann, R.; Holtappels, P.; Graule, T. Proton Diffusivity in the $\mathrm{BaZr}_{0.9} \mathrm{Y}_{0.1} \mathrm{O}_{3-\delta}$ Proton Conductor. J. Appl. Electrochem. 2009, 39 (4), 471-475.

(93) Kreuer, K. Aspects of the Formation and Mobility of Protonic Charge Carriers and the Stability of Perovskite-Type Oxides. Solid State Ionics 1999, 125 (1-4), 285-302.

(94) Kreuer, K. D.; Adams, S.; Münch, W.; Fuchs, A.; Klock, U.; Maier, J. Proton Conducting Alkaline Earth Zirconates and Titanates for High Drain Electrochemical Applications. Solid State Ionics 2001, 145 (1-4), 295-306. 
(95) Pionke, M.; Mono, T.; Schweika, W.; Springer, T.; Schober, H. Investigation of the Hydrogen Mobility in a Mixed Perovskite: $\mathrm{Ba}\left[\mathrm{Ca}_{(1+\mathrm{x}) / 3} \mathrm{Nb}_{(2-\mathrm{x}) / 3}\right] \mathrm{O}_{3-\mathrm{x} / 2}$ by Quasielastic Neutron Scattering. Solid State Ionics 1997, 97 (1-4), 497-504.

(96) Mather, G. C.; Heras-Juaristi, G.; Ritter, C.; Fuentes, R. O.; Chinelatto, A. L.; Pérez-Coll, D.; Amador, U. Phase Transitions, Chemical Expansion, and Deuteron Sites in the $\mathrm{BaZr}_{0.7} \mathrm{Ce}_{0.2} \mathrm{Y}_{0.1} \mathrm{O}_{3-\delta}$ Proton Conductor. Chem. Mater. 2016, 28 (12), 4292-4299.

(97) Knöchel, P. L.; Keenan, P. J.; Loho, C.; Reitz, C.; Witte, R.; Knight, K. S.; Wright, A. J.; Hahn, H.; Slater, P. R.; Clemens, O. Synthesis, Structural Characterisation and Proton Conduction of Two New Hydrated Phases of Barium Ferrite $\mathrm{BaFeO}_{2.5-\mathrm{x}}(\mathrm{OH})_{2 \mathrm{x}}$. J. Mater. Chem. A 2016, 4 (9), 3415-3430.

(98) Waidha, A. I.; Lepple, M.; Wissel, K.; Benes, A.; Wollstadt, S.; Slater, P. R.; Fortes, A. D.; Clemens, O. Synthesis, Structure and Electrical Conductivity of a New Perovskite Type Barium Cobaltate $\mathrm{BaCoO}_{1.80}(\mathrm{OH})_{0.86}$. Dalt. Trans. 2018, 47 (32), 11136-11145.

(99) Aroyo, M. I.; Perez-Mato, J. M.; Orobengoa, D.; Tasci, E.; Flor, G. de la; Kirov, A. Crystallography Online: Bilbao Crystallographic Server. Bulg. Chem. Commun. 2011, 43 (2), 183-197.

(100) Aroyo, M. I.; Perez-Mato, J. M.; Capillas, C.; Kroumova, E.; Ivantchev, S.; Madariaga, G.; Kirov, A.; Wondratschek, H. Bilbao Crystallographic Server: I. Databases and Crystallographic Computing Programs. Z. Kristallogr. - Cryst. Mater. 2006, 221 (1), 15-27.

(101) Aroyo, M. I.; Kirov, A.; Capillas, C.; Perez-Mato, J. M.; Wondratschek, H. Bilbao Crystallographic Server. II. Representations of Crystallographic Point Groups and Space Groups. Acta Crystallogr., Sect. A: Found. Crystallogr. 2006, 62 (2), 115-128.

(102) Hermet, J.; Torrent, M.; Bottin, F.; Dezanneau, G.; Geneste, G. Hydrogen Diffusion in the Protonic Conductor $\mathrm{BaCe}_{1-\mathrm{x}} \mathrm{Gd}_{\mathrm{x}} \mathrm{O}_{3-\mathrm{x} / 2}$ from density finctional theory-. Phys. Rev. B: Condens. Matter Mater. Phys. 2013, 87 (10), 104303.

(103) Jeong, Y.-C.; Kim, B.-K.; Kim, Y.-C. Proton Migration in Bulk Orthorhombic Barium Cerate Using Density Functional Theory. Solid State Ionics 2014, 259, 1-8. 